JR只D

\title{
Characteristics of the audiometric 4,000 Hz notch (744,553 veterans) and the 3,000, 4,000, and 6,000 Hz notches (539,932 veterans)
}

\author{
Richard H. Wilson, PhD; ${ }^{*}$ Rachel McArdle, $\mathbf{P h D}^{\mathbf{2}}$ \\ ${ }^{1}$ James H. Quillen Department of Veterans Affairs (VA) Medical Center, Mountain Home, TN; and Department of Audiol- \\ ogy and Speech-Language Pathology, East Tennessee State University, Johnson City, TN; ${ }^{2}$ Bay Pines VA Healthcare Sys- \\ tem, Bay Pines, FL; and Department of Communication Sciences and Disorders, University of South Florida, Tampa, FL
}

\begin{abstract}
The purpose of this study was to examine the prevalence and characteristics of audiograms that are notched (1) at $4,000 \mathrm{~Hz}$ and (2) at 3,000, 4,000, and/or 6,000 Hz. Bilateral audiograms from 1,000,001 veterans were obtained from Department of Veterans Affairs archives; after "cleaning” algorithms were applied, 744,553 participants (mean age = $63.5 \mathrm{yr}$ ) were included in the 4,000 $\mathrm{Hz}$ notch analysis (group 1) and 539,932 participants (mean age $=62.2 \mathrm{yr}$ ) were included in the $3,000,4,000$, and/or 6,000 Hz notch analysis (group 2). A notch was defined when the threshold at the notch frequency $(3,000$, 4,000 , or $6,000 \mathrm{~Hz}$ ) minus the $2,000 \mathrm{~Hz}$ threshold and the threshold at the notch frequency minus the $8,000 \mathrm{~Hz}$ threshold both were greater than or equal to $10 \mathrm{~dB}$. In group 1, 77.1\% did not have a notch at $4,000 \mathrm{~Hz}$. In group 2, 65.3\% did not have a notch at 3,000, 4,000, or 6,000 Hz; $12.4 \%$ had bilateral notches, $11.7 \%$ had left ear notches, and $10.7 \%$ had right ear notches. The notches were about twice as deep on the low-frequency side of the notch than on the high-frequency side. The mean left ear and right ear notch depths were about the same (23 dB), with mode notch depths in the 15.0 to $17.5 \mathrm{~dB}$ range.
\end{abstract}

Key words: audiogram, bilateral, hearing loss, high-frequency, multisite, noise exposure, noise notch, notched audiogram, unilateral, veterans.

\section{INTRODUCTION}

Air-conduction audiograms with 3,000, 4,000, and/or $6,000 \mathrm{~Hz}$ thresholds at higher hearing levels (HLs) than the adjacent 2,000 and 8,000 Hz thresholds are historically referred to as "notched audiograms." Since the ini- tial observations of the notched audiograms, noise exposure has been the designated causal factor [1-4]. Evidence from more recent animal and human studies has led many investigators to question (1) whether or not noise exposure is the sole contributing factor to the notched audiogram and (2) the pathophysiology of noiseinduced hearing loss [5-19]. Additionally, notched audiograms are reportedly associated with individuals who have no marked history of noise exposure; conversely, some individuals with a substantial history of noise exposure exhibit no evidence of a notched audiogram [14,20]. Intuitively, because noise exposure typically occurs in a

\footnotetext{
*For a thorough review, see Wilson RH. Some observations on the nature of the audiometric $4000 \mathrm{~Hz}$ notch: data from 3430 veterans. J Am Acad Audiol. 2011;22(1):23-33.
}

Abbreviations: $\mathrm{AU}=$ auris utraque, $\mathrm{DALC}=$ Denver Acquisition and Logistics Center, EHLS = Epidemiology of Hearing Loss Study, HFPTA = high-frequency pure-tone average, HL = hearing level, LE = left ear, PTA = pure-tone average, QUASAR = Quality: Audiology and Speech Analysis and Reporting, $\mathrm{RE}=$ right ear, $\mathrm{SD}=$ standard deviation, $\mathrm{VA}=$ Department of Veterans Affairs, VistA = Veterans Health Information Systems and Technology Architecture.

*Address all correspondence to Richard $\mathrm{H}$. Wilson, PhD; Audiology Research (126), VA Medical Center, Mountain Home, TN 37684-4000; 423-979-3561; fax: 423-979-3403. Email: richard.wilson2@va.gov

http://dx.doi.org/10.1682/JRRD.2011.11.0225 
free or sound field, it is reasonable to expect both ears to be equally affected by noise incidences. This line of reasoning may not, in fact, be the case. Recent observations indicate that it is more common to observe unilateral high-frequency notches than bilateral high-frequency notches [20-23]. Support of this plethora of unilateral high-frequency notches was provided by Nondahl et al. [18, p. 698: Table 1], who evaluated audiometric notches of 2,159 participants in the Epidemiology of Hearing Loss Study (EHLS) at Beaver Dam, Wisconsin [24]. Nondahl et al. examined the high-frequency audiometric notches by using four algorithms [18, p. 698: Table 1], three of which required a notch be present in one or both ears [22,25-26], whereas the fourth required notches be present in both ears [27]. Using these strict definitions, 31.7 [25], 25.9 [22], 47.2 [26], and 11.7 percent [27] of the EHLS participants had notches. When the first three algorithms were adjusted to include a notch in both ears, the EHLS prevalences dropped to 9.1, 4.7, and 24.9 percent, respectively, which are in better agreement with the 11.7 percent prevalence reported for the Hoffman et al. algorithm [27]. The implication from these differing results is that there were more unilateral notches than bilateral notches in this population-based study.

A recent study from our laboratory substantiated this observation with data from 3,430 veterans [28]. In that study, notched audiograms at $4,000 \mathrm{~Hz}$ were observed in 41.1 percent of the participants in at least one ear, with 15.4 percent having bilateral notches (auris utraque [AU] or "both ears"), 13.8 percent having unilateral left ear (LE) notches, and 11.9 percent having unilateral right ear (RE) notches. (Note: These percentages are based on audiogram pairs that were not reported in the original report.) Thus, of the audiogram pairs with notches at 4,000 Hz, 37.5 percent had bilateral notches and 62.5 percent had unilateral notches.

Although the Wilson report had a sizable group of participants [28], previous multisite clinical trials in the Department of Veterans Affairs (VA) have revealed significant site differences based on geographic location. One example is a current VA Rehabilitation Research and Development-funded multisite study designed to look at the efficacy of computerized auditory training with more than 250 participants recruited from the (1) Bay Pines VA Healthcare System, Bay Pines, Florida; (2) James H. Quillen VA Medical Center, Mountain Home, Tennessee; and (3) Portland VA Medical Center, Portland, Oregon. Multiple significant baseline characteristic differences were found among sites. Specifically, participants recruited from Bay Pines were significantly older with lower levels of education and reading ability than the participants recruited from the other two sites. There were no differences in pure-tone averages (PTAs); however, the participants from Bay Pines reported significantly fewer comorbidities and lower hearing handicap as measured by the Hearing Handicap Inventory for the Elderly [29]. Because of these recognized site differences, the current study purposed to extend the Wilson report [28] on veteran audiometric data to a substantially larger sample of participants from throughout the VA system and to include an examination of the interoctave frequencies that often are associated with high-frequency audiometric notches, viz., 3,000 and 6,000 Hz. Additionally, the larger sample enabled examination of several relationships among the audiometric-notch variables that were not possible to examine with the smaller data set. These goals were accomplished with audiometric data from 1,000,001 veterans who were entered through the Quality: Audiology and Speech Analysis and Reporting (QUASAR) Audiogram Module at VA facilities across the nation and archived at the Denver Acquisition and Logistics Center (DALC), which is the component of the VA through which hearing aids and associated devices are procured and dispensed to veterans. The QUASAR Audiogram Module, which is not restricted to patients receiving hearing aids, is a Windows-based graphical user interface, developed to simplify and enhance the entry, display, and use of information obtained during an audiometric examination of a patient, that can be accessed from the Computerized Patient Record System "Tools" menu. The QUASAR Audiogram Module includes components that reside on two systems (the local facility Veterans Health Information Systems and Technology Architecture [VistA] system and the DALC system) that use the VA VistA MailMan interface to pass data from the local site to the DALC database.

\section{METHODS}

The data were collected by audiologists or audiology doctoral students during routine clinical evaluations. Earphone-specific information was not available in the DALC database, but a DALC survey indicated that insert earphones were used in a little over half the evaluations. Reports from a sampling of the VA clinics indicate that a majority use the modified Hughson-Westlake procedure to establish pure-tone thresholds [30]. 
Throughout the analyses conducted in this study, the $\mathrm{RE}$ and LE audiograms of each participant were linked such that if the audiometric data from one ear did not meet the inclusion criteria, then that participant was excluded from the study. This coupling of the LE and RE audiograms of each participant (i.e., audiogram pairs) was necessary because of the prevalence issue of unilateral and bilateral notches being investigated. In addition to the pure-tone audiograms, the DALC repository provided the ages of the participants, except for those $90 \mathrm{yr}$ and older. Because of privacy sensitivity issues, participants $\geq 90$ yr are considered not by their individual ages but as a group age of $90 \mathrm{yr}$. Of the initial 1,000,001 audiometric data sets, 208 were $<20$ yr of age, which represented 0.02 percent of the participant pool. Because the age analyses planned were based on decade intervals, this small number of 18 and 19 yr-olds was eliminated from further analyses, leaving 999,793 veterans. A second exclusion criterion was a conductive component that was defined as an air-bone gap in either ear at $1,000 \mathrm{~Hz}$ of $\geq 15 \mathrm{~dB}$. This criterion excluded 51,137 participants, leaving 948,656 participants or audiogram pairs. This article is descriptive in nature to illustrate audiometric configurations, specifically notched audiograms, with veteran sample sizes never before reported. Owing to the size of the data sets, trivial differences between groups become statistically significant. Given no hypotheses are being tested throughout this article, no inferential statistics are included.

The analyses of the data are descriptive from two points of view: age and depth of the audiometric notch. The analyses of the cross-sectional age data incorporated eight decade intervals from 20 to $29 \mathrm{yr}$ to $\geq 90 \mathrm{yr}$. The audiometric notch was defined when the thresholds at 2,000 and 8,000 $\mathrm{Hz}$ were both minimally at HLs $10 \mathrm{~dB}$ lower than (better than) the threshold at the notch frequency of interest $(3,000,4,000$, or $6,000 \mathrm{~Hz})$, which is the same notch definition used in Wilson [28] and similar to the notch definition used by Coles et al. [25]. Although this rather liberal definition of an audiometric notch has been used previously and casts a wide net, in most of this report, the audiometric notches are analyzed in terms of nine notch depths from $10 \mathrm{~dB}$ to $50 \mathrm{~dB}^{+}$in $2.5 \mathrm{~dB}$ increments (10.0-12.5 dB, 15.0-17.5 dB, etc.), which enables examination of the data with respect to a multitude of notch-depth definitions.

Because the issue of unilateral and bilateral notches was paramount in this study, an additional inclusion crite- rion was that each participant was required to have measurable thresholds in both ears at 2,000, 4,000, and 8,000 Hz, which were necessary to define a $4,000 \mathrm{~Hz}$ notch. Participants meeting these inclusion criteria were analyzed as group 1 (mean \pm standard deviation [SD] age $=63.5 \pm$ $16.1 \mathrm{yr}$ ). This criterion reduced the number of audiogram pairs to 744,553 , which is about 75 percent of the original participant pool. The data in Figure 1 depict the number of participants in each age year (circles) with a superimposed histogram that indicates the percentage of participants in each age decade. For the evaluation of the 3,000, 4,000, and $6,000 \mathrm{~Hz}$ notches, an additional criterion was that thresholds at 3,000 and 6,000 $\mathrm{Hz}$ also had to be measurable in both ears, which reduced the number of audiogram pairs to 539,932 for that particular analysis. The participants meeting these second inclusion criteria were analyzed as group 2 (mean \pm SD age $=62.2 \pm 16.3 \mathrm{yr}$ ).

Finally, the DALC database provided no indications of the types, amounts, and durations of noise exposure experienced by each participant, which precluded any examination of the possible relations between noise exposure and the pure-tone audiogram. It has long been assumed that military personnel experience more noise exposure than nonmilitary individuals. The implication of this assumption, therefore, has been that military personnel exhibit more hearing loss than nonmilitary individuals. Recent data from the EHLS [24] indicate that, on average, the pure-tone thresholds of male military veterans are not different from

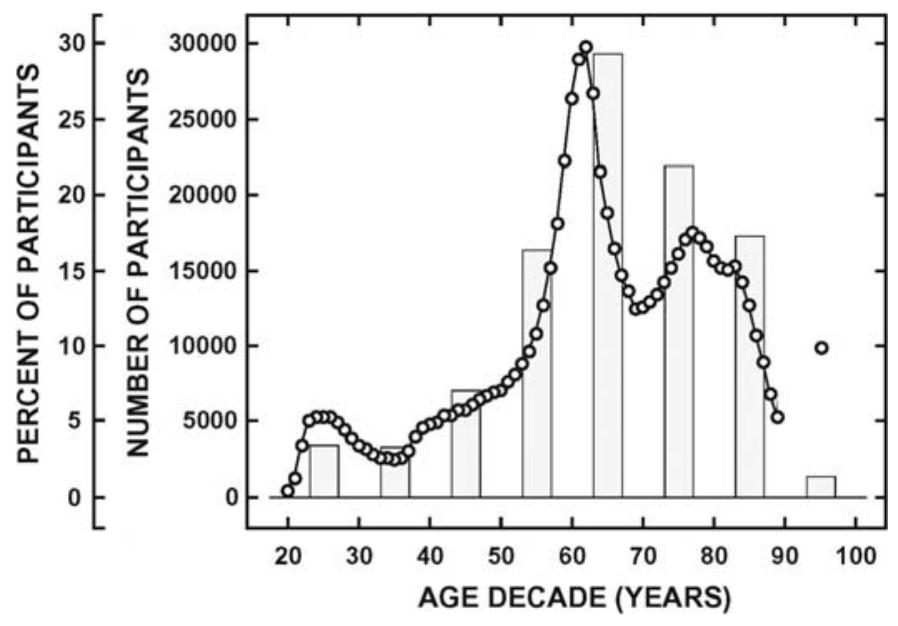

Figure 1.

Number of participants in each age year (circles) and histogram of percentage of participants in each of eight age decades. $n=$ 744,553 participants. 
the thresholds of their male civilian counterparts [31]. The data from 995 veterans in that study also indicated that 72.1 percent of the veterans were not involved in the frontline or combat support activities where most noise exposure would be expected to occur; the DALC database should be characterized by similar distributions.

\section{RESULTS}

The analyses and presentations of the data for group 1 and group 2 follow similar patterns, with each using three subheadings, viz., notch prevalence, notch depth, and mean audiograms. First, for each of the two groupings, the mean overall LE and RE audiograms are presented for group 1 and group 2 . Second, the data are presented for each age decade in terms of the percentage of participants with unnotched audiograms and the percentage with notched audiograms. The notched category then is parsed into the percentage of participants with unilateral LE, unilateral RE, and bilateral notches. Third, the number and percentage of participants with notched audiograms are presented for each age group and each ear along with measures of central tendency for the notch depths. Fourth, a comparison by ear and by age group of the percentage of unilateral and bilateral notched audiograms is presented. Fifth, for each age group and each ear, the mean threshold differences between 2,000 and 4,000 Hz and between 800 and 4,000 Hz are listed, from which a symmetry ratio of the notch is defined and described. Sixth, the percentages of notched LE and RE audiograms in each of the nine notch-depth categories are presented and then expanded into a presentation of the notched depth by ear and by age decade. Seventh, the percentage of unilateral and bilateral RE notches is presented for each of the nine notch-depth categories. Eighth, for the individuals with bilateral notches, the notch depth of the RE is compared with the notch depth of the LE. Finally, the mean RE audiograms for the unnotched, notched, and unnotched-notched combined groupings are presented for each of the age groups and are recast to show the notched and unnotched mean audiograms as a function of the age group. For several of the presentation sections, the data for one ear are graphed, whereas the data from the other ear are tabularized.

\section{Group 1 (4,000 Hz Data)}

The mean audiograms for the LE and RE of the 744,553 participants included in the analyses of the 4,000 $\mathrm{Hz}$ notch data are listed in Table 1. The mean audiograms reflect mild-to-moderate, high-frequency sensorineural hearing losses with mean three-frequency PTAs (500, 1,000, and 2,000 Hz) of 30.4 and $29.5 \mathrm{~dB}$ HL [32] (SD of 16.8 and $16.6 \mathrm{~dB}$ ) for the LE and RE, respectively. The mean high-frequency PTAs (HFPTAs) $(1,000$, 2,000, and 4,000 Hz) were 41.5 and $40.0 \mathrm{~dB}$ HL for the $\mathrm{LE}$ and RE, respectively (both with SD of $19.0 \mathrm{~dB}$ ). The mean threshold differences between ears at 250,500, and $1,000 \mathrm{~Hz}$ are $<0.5 \mathrm{~dB}$. At 2,000 and 4,000 Hz, however, the mean RE thresholds were at HLs about $2 \mathrm{~dB}$ lower (better) than the mean LE thresholds at those frequencies. At $8,000 \mathrm{~Hz}$, the mean RE threshold was $1.1 \mathrm{~dB}$ lower than the mean LE threshold. Almost identical relations were observed between the mean frequency-specific thresholds for the LEs and REs in our earlier study with 3,430 veterans [28]. A common characteristic of largescale studies, including those that are population based, is lower (better) high-frequency thresholds in the RE than in the LE [24,33-42]. Finally, from the mean threshold data in Table 1, there is no evidence of an audiometric notch at 4,000 Hz, the reason for which will become apparent as the data analyses develop in the subsequent sections.

\section{Group 1 Notch Prevalence}

The percentage of participants in each of the eight age decades having air-conduction audiograms with no 4,000

Table 1.

Mean \pm standard deviation (SD) left ear (LE) and right ear (RE) pure-tone air-conduction thresholds (decibels hearing level [32]) from 744,553 individuals between ages of 20 and $90+$ yr (mean \pm SD age $63.5 \pm 16.1$ ).

\begin{tabular}{lcccccc}
\hline \multirow{2}{*}{ Ear } & \multicolumn{5}{c}{ Frequency (Hz) } \\
\cline { 2 - 6 } & $\mathbf{2 5 0}$ & $\mathbf{5 0 0}$ & $\mathbf{1 , 0 0 0}$ & $\mathbf{2 , 0 0 0}$ & $\mathbf{4 , 0 0 0}$ & $\mathbf{8 , 0 0 0}$ \\
\hline LE (Mean \pm SD) & $22.3 \pm 14.3$ & $23.7 \pm 15.3$ & $27.8 \pm 17.7$ & $39.6 \pm 2.4$ & $57.0 \pm 23.9$ & $60.5 \pm 26.2$ \\
RE (Mean \pm SD) & $22.2 \pm 14.1$ & $23.5 \pm 15.2$ & $27.4 \pm 17.3$ & $37.5 \pm 22.1$ & $55.0 \pm 24.5$ & $59.4 \pm 26.7$ \\
Difference (RE - LE) & -0.1 & -0.2 & -0.4 & -2.1 & -2.0 & -1.1 \\
\hline \hline
\end{tabular}


$\mathrm{Hz}$ notches (squares) and with $\mathrm{LE}$ and/or RE 4,000 Hz notches (pluses) are shown in Figure 2. A breakdown of the $\mathrm{LE}$ and/or RE 4,000 $\mathrm{Hz}$ data also is provided with the percentage of participants with LE notches (Xs), RE notches (circles), and bilateral notches (AU, triangles) depicted. The number of participants in each age decade is listed on the upper abscissa. Table 2 lists the numbers of participants by age and notch status category upon which the percentages in Figure 2 are based. The majority of the 744,553 audiogram pairs (573,850 or $77.1 \%$ ) did not have a $4,000 \mathrm{~Hz}$ notch in the air-conduction audiogram of either ear, which was the contributing factor to the mean unnotched audiograms in Table $\mathbf{1}$. Of the remaining 170,703 audiogram pairs with a 4,000 $\mathrm{Hz}$ notch in at least one ear (22.9\%), 62,088 (8.3\%) had a notch only in the LE, 56,884 (7.6\%) had a notch only in the RE, and 51,731 (6.9\%) had bilateral notches. Although the prevalence of notched audiograms is decreased in the current study (22.9\%) in comparison with the Wilson study (41.1\%) [28], the relation between the percentage of unilateral and bilateral notches observed in the earlier study is substanti-

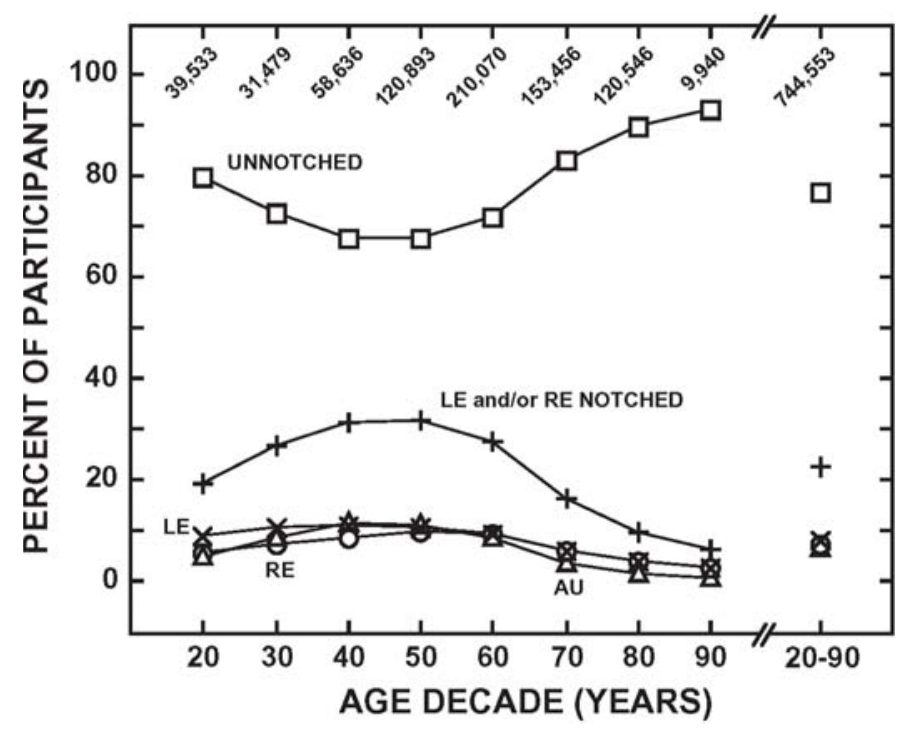

Figure 2.

Percentage of participants in each age group who had no $4,000 \mathrm{~Hz}$ audiometric notch (squares) or left ear (LE) and/or right ear (RE) 4,000 Hz notch (pluses) are shown. Latter category is parsed into three subgroups: unilateral LE $4,000 \mathrm{~Hz}$ notch (Xs), unilateral RE 4,000 Hz notch (circles), and bilateral 4,000 Hz notches ( $\mathrm{AU}$, triangles). Number of participants in each age group is indicated at top of graph. ated in the current data. In the earlier study, 37.5 percent of the notched audiograms were bilateral, whereas 62.5 percent were unilateral. The corresponding numbers from the current study are similar, with 30.3 percent $(51,731)$ having bilateral notches and 69.7 percent $(118,972)$ having unilateral notches. The data indicate that unilateral 4,000 Hz notches are much more common than bilateral 4,000 Hz notches, with slightly more LE notches than RE notches. Data from other studies support the disparity between unilateral and bilateral notches. For example, Gates et al. indicated in a population-based study of 1,186 participants that 60 percent of the notches were unilateral, with the remaining 40 percent bilateral [21]. A higher ratio was reported by Osei-Lah and Yeoh [20], with 75 percent unilateral and 25 percent bilateral. Finally, depending on the notch definition, Nondahl et al. reported for the EHLS that 25.9 to 47.2 percent exhibited notched audiograms in at least one ear, with the prevalence dropping to 9.1 to 24.9 percent when notches in both ears were used in the definition of a notch [18].

As can be seen in Figure 2, the percentage of LE and/ or RE notched audiograms (pluses) reaches a maximum in the $50 \mathrm{yr}$ decade (32.1\%), with declining numbers in the lower and higher decades. A similar observation was made in our earlier article in which the peak for each ear was in the $50 \mathrm{yr}$ decade at 35 to 37 percent [28, p. 27: Figure 2]. For the unilateral LE and RE notch categories and the bilateral notch category, the percentage of participants is fairly constant at 9 to 11 percent between the 30 and $60 \mathrm{yr}$ decade groups, declining rapidly thereafter to $<3$ percent with notches in the $90 \mathrm{yr}$ decade. As others have indicated (e.g., Gates et al. [43]), the decline in the prevalence of notches as a function of age is attributable to aging effects on the auditory system that are reflected in increasingly higher (poorer) thresholds at $8,000 \mathrm{~Hz}$ that ultimately preclude the formation of a notch in that the 4,000 Hz minus 8,000 Hz threshold difference becomes $<10 \mathrm{~dB}$, progressing to a negative value.

The data in Table 3 summarize by age decade the number of participants, the percentages of LE and RE notches at 4,000 Hz, and the mean notch depths in decibels that were obtained from the 744,553 veterans. The percentage of participants with $4,000 \mathrm{~Hz}$ notches increases for both the LEs and REs through the 40 and 50 yr decades (22\%-23\%), with a sharp decline thereafter through the $90 \mathrm{yr}$ decade (4\%). The prevalence and notch characteristics are remarkably similar for the LE and RE in each age decade. A consistent exception to this 
JRRD, Volume 50, Number 1, 2013

Table 2.

Number of participants in each age decade who had no audiometric notch at 4,000 Hz or who had one or combination of 4,000 $\mathrm{Hz}$ notches.

\begin{tabular}{|c|c|c|c|c|c|c|c|c|c|}
\hline \multirow{2}{*}{ Condition } & \multicolumn{8}{|c|}{ Age Decade (yr) } & \multirow{2}{*}{ Overal } \\
\hline & $20 \mathrm{~s}$ & $30 \mathrm{~s}$ & $40 \mathrm{~s}$ & $50 \mathrm{~s}$ & $60 \mathrm{~s}$ & $70 \mathrm{~s}$ & $80 \mathrm{~s}$ & 90s & \\
\hline $\bar{n}$ & 39,533 & 31,479 & 58,636 & 120,893 & 210,070 & 153,456 & 120,546 & 9,940 & 744,553 \\
\hline No Notch & 31,708 & 22,975 & 39,949 & 82,048 & 151,605 & 127,974 & 108,318 & 9,273 & 573,850 \\
\hline LE Notch & 3,579 & 3,371 & 6,671 & 12,903 & 20,244 & 9,909 & 5,123 & 288 & 62,088 \\
\hline RE Notch & 2,317 & 2,430 & 5,122 & 12,060 & 19,980 & 9,760 & 4,933 & 282 & 56,884 \\
\hline AU Notch & 1,929 & 2,703 & 6,894 & 13,882 & 18,241 & 5,813 & 2,172 & 97 & 51,731 \\
\hline 1 or 2 Notches & 7,825 & 8,504 & 18,687 & 38,845 & 58,465 & 25,482 & 12,228 & 667 & 170,703 \\
\hline
\end{tabular}

Table 3.

Number, percentage, and notch depth of left and right ear 4,000 Hz notches.

\begin{tabular}{|c|c|c|c|c|c|c|c|}
\hline \multirow[b]{2}{*}{$\begin{array}{l}\text { Age Decade } \\
\text { (yr) }\end{array}$} & \multirow[b]{2}{*}{ Total $n$} & \multicolumn{3}{|c|}{ Left Ear } & \multicolumn{3}{|c|}{ Right Ear } \\
\hline & & Notch $n$ & $\%$ & $\begin{array}{c}\text { Notch Depth }(\mathrm{dB}) \\
\text { Mean } \pm \text { SD }\end{array}$ & Notch $n$ & $\%$ & $\begin{array}{c}\text { Notch Depth }(\mathrm{dB}) \\
\text { Mean } \pm \text { SD }\end{array}$ \\
\hline $20 \mathrm{~s}$ & 39,533 & 5,507 & 13.9 & $22.2 \pm 11.2$ & 4,247 & 10.7 & $21.4 \pm 11.1$ \\
\hline $30 \mathrm{~s}$ & 31,479 & 6,074 & 19.3 & $22.7 \pm 10.5$ & 5,133 & 16.3 & $22.3 \pm 10.8$ \\
\hline $40 \mathrm{~s}$ & 58,636 & 13,565 & 23.1 & $23.9 \pm 10.2$ & 12,016 & 20.5 & $23.8 \pm 10.2$ \\
\hline $50 \mathrm{~s}$ & 120,893 & 26,785 & 22.2 & $23.8 \pm 9.2$ & 25,942 & 21.5 & $24.7 \pm 9.6$ \\
\hline $60 \mathrm{~s}$ & 210,070 & 38,485 & 18.3 & $23.8 \pm 9.2$ & 38,221 & 18.2 & $24.3 \pm 9.3$ \\
\hline $70 \mathrm{~s}$ & 153,456 & 15,722 & 10.2 & $20.8 \pm 8.3$ & 15,573 & 10.1 & $21.4 \pm 8.6$ \\
\hline $80 \mathrm{~s}$ & 120,546 & 7,295 & 6.1 & $18.8 \pm 7.1$ & 7,105 & 5.9 & $19.3 \pm 7.4$ \\
\hline $90 \mathrm{~s}$ & 9,940 & 385 & 3.9 & $17.5 \pm 6.3$ & 379 & 3.8 & $17.9 \pm 6.9$ \\
\hline 20s-90s & 744,553 & 113,818 & 15.3 & $23.1 \pm 9.5$ & 108,616 & 14.6 & $23.4 \pm 9.5$ \\
\hline
\end{tabular}

similarity is the $\sim 3$ percent higher prevalence of LE notches than RE notches in the 20 to 50 yr decades. Overall, there were 113,818 (15.3\%) notched LE audiograms and 108,616 (14.6\%) notched RE audiograms, which is about half the prevalence of notched audiograms found with the 3,430 veterans involved in our earlier study in which 28.8 percent of the LE audiograms and 27.1 percent of the RE audiograms were notched at $4,000 \mathrm{~Hz}$ [28, p. 28: Table 2]. Although both studies involved identical notch definitions, similar participant age ranges, and veterans who were seeking help for their hearing problems, the prevalence differences must be in part attributable to the different size samples and different sample characteristics that were involved in the two studies. The mean ages of the two studies were similar, $62.2 \mathrm{yr}$ in the earlier study and $63.5 \mathrm{yr}$ in the current study. The age SD (12.8 $\mathrm{yr}$ in the earlier study and $16.1 \mathrm{yr}$ in the current study), however, suggested slightly different age distributions. Proportionally, the current study had 6 percent more participants in the age decades $<60 \mathrm{yr}$ and 8 percent more in the $80 \mathrm{yr}$ decade. These slight differences in age distribu- tions between the two studies could account for some of the discrepancy in notch prevalences, but probably not all. Another possible reason for the discrepancy between the notch prevalences in the current study and in the previous VA study might be related to the site differences, previously mentioned in the "Introduction," in which the rate of comorbidities and various auditory measures differed among VA facilities. Site-specific differences in prevalence will be explored in a future report.

Finally, regarding the prevalence of $4,000 \mathrm{~Hz}$ notches, we were interested in examining in more detail the prevalence of $4,000 \mathrm{~Hz}$ notches in terms of unilateral and bilateral occurrences. The histograms in Figure 3 depict the prevalence of unilateral and bilateral $4,000 \mathrm{~Hz}$ notched audiograms for the LE and RE for each of the eight decades. The data indicate that the percentage of audiograms with a unilateral notch (striped) or bilateral notch (shaded) varied as a function of age and, to some degree, as a function of ear. The LE in the 20 and $30 \mathrm{yr}$ decades clearly has more unilateral notches than bilateral notches, a relation that is only reflected in the RE by the 


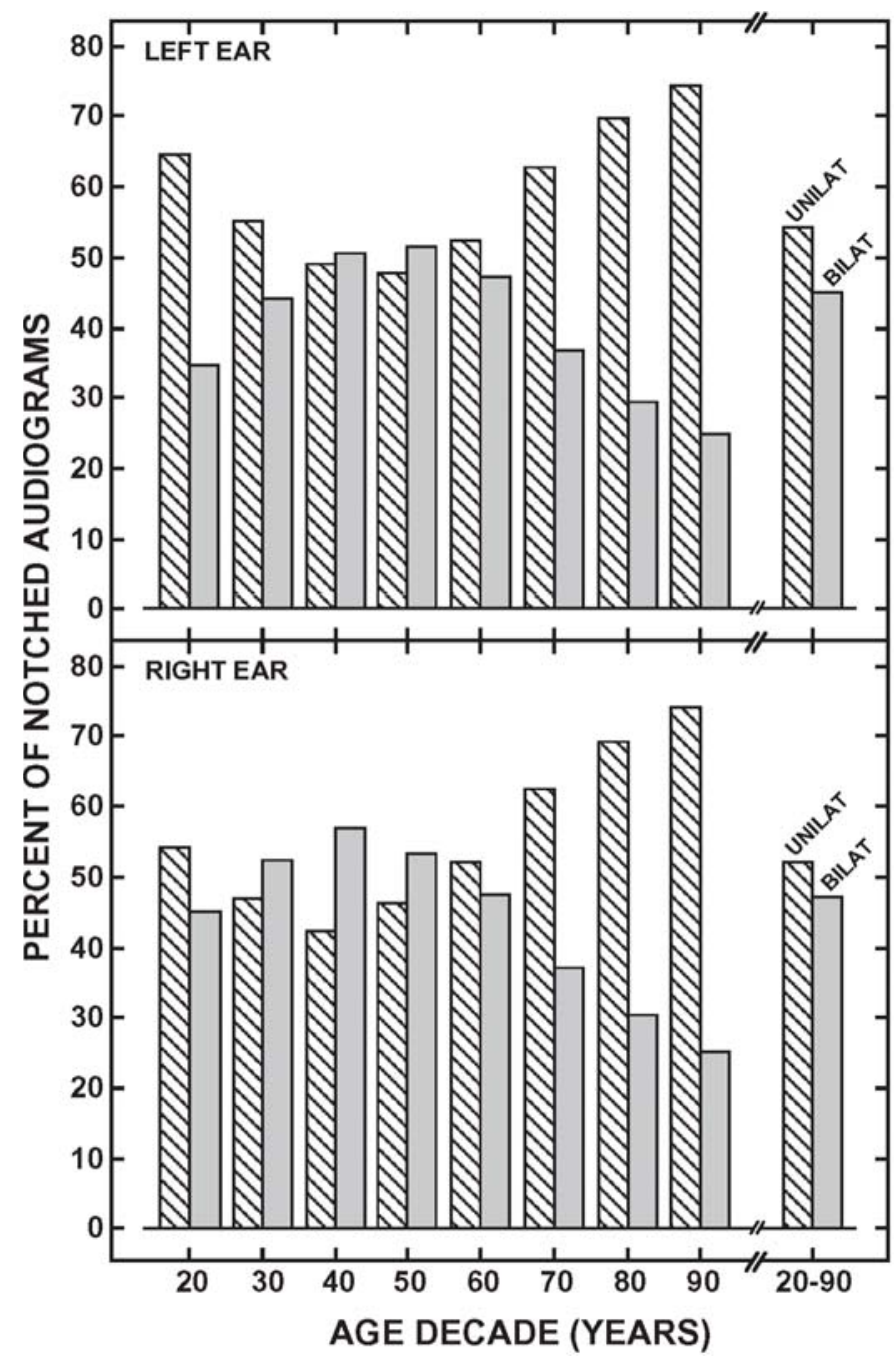

Figure 3.

Histograms for eight age categories of percentage of notches present unilaterally (UNILAT) in target ear (striped) versus present in target ear when notches were present bilaterally (BILAT, shaded). Left ear $n=113,818$; right ear $n=108,616$.

20 yr decade. In the 40 to $60 \mathrm{yr}$ decades, the percentage of unilateral and bilateral notches is mixed, whereas in the 70 to $90 \mathrm{yr}$ decades, there are increasingly far more unilateral notches than bilateral notches. The reason for such a discrepancy between the prevalence of unilateral and bilateral notches in the last three decades certainly suggests underlying mechanism differences between the individuals with unilateral and bilateral notches, but the nature of that mechanism cannot be determined from the current data.

\section{Group 1 Notch Depths}

A notch at $4,000 \mathrm{~Hz}$ was defined when the $4,000 \mathrm{~Hz}$ threshold minus the 2,000 $\mathrm{Hz}$ threshold and the $4,000 \mathrm{~Hz}$ threshold minus the $8,000 \mathrm{~Hz}$ threshold both were $\geq 10 \mathrm{~dB}$. The mean notch depth (in decibels) was simply the average of the two aforementioned threshold differences, which, because of the $5 \mathrm{~dB}$ step sizes involved in the threshold measures, produced mean difference data in $2.5 \mathrm{~dB}$ intervals. From Table 3, the mean notch depth of the $113,818 \mathrm{LE}$ notches was $23.1 \mathrm{~dB}$ and the mean notch depth of the 108,616 RE notches was $23.4 \mathrm{~dB}$; both SD values were $9.5 \mathrm{~dB}$. Because the two threshold differences constitute the opposing sides of the notch, their relation can be expressed as a symmetry ratio:

$$
\text { Symmetry Ratio }=\frac{(4,000 \mathrm{~Hz} \text { threshold }-2,000 \mathrm{~Hz} \text { threshold })}{(4,000 \mathrm{~Hz} \text { threshold }-8,000 \mathrm{~Hz} \text { threshold })} .
$$

Table 4 lists the respective mean threshold differences (and SD) and the corresponding mean symmetry ratios of the LE and RE notches as a function of age. For both ears, the low-frequency side of the $4,000 \mathrm{~Hz}$ notch was about twice as deep (or steep) as the high-frequency side of the notch with an overall $\sim 30 \mathrm{~dB}$ difference (SD = $16 \mathrm{~dB}$ ) between the 4,000 and $2,000 \mathrm{~Hz}$ thresholds and a $16.6 \mathrm{~dB}$ difference ( $\mathrm{SD}=8.3 \mathrm{~dB}$ ) between the 4,000 and $8,000 \mathrm{~Hz}$ thresholds. The overall mean symmetry ratios were 2.1 with SD of 1.4. As shown in Table 4, the symmetry ratio changed as a function of age, systematically increasing from 1.4 in the $20 \mathrm{yr}$ decade to 1.9 to 2.3 in the 50 to $90 \mathrm{yr}$ decades. Thus, the low-frequency side of the notch with the younger participants was only slightly larger (steeper) than the high-frequency side, whereas with the older participants the low-frequency side was substantially steeper than the high-frequency side. Finally, the histogram in Figure $\mathbf{4}$ gives the distribution of the percentage of LEs and REs that had notch symmetry ratios in each of the eight symmetry categories, the first being 0 to 0.9 . The distributions for both ears were essentially the same. About 75 percent of the symmetry ratios were $<3$, with 40.3 percent of both ears having symmetry ratios between 1 and 1.9. Symmetry ratios $>4$ characterized only about 12 percent of the notches in each ear.

Four additional aspects of the notch depth data were evaluated. First were the overall distributions of LE and RE notch depths that are depicted by the histograms in Figure 5. The data indicate that the percentage of LE and $\mathrm{RE}$ notched audiograms are about the same for the various 
JRRD, Volume 50, Number 1, 2013

Table 4.

Mean threshold differences (and standard deviation [SD]) between 4,000 and 2,000 Hz thresholds and between 4,000 and 8,000 Hz thresholds for left ear and right ear of various age groups, along with symmetry ratio of threshold differences.

\begin{tabular}{|c|c|c|c|c|}
\hline \multirow{2}{*}{$\begin{array}{c}\text { Age Decade } \\
\text { (yr) }\end{array}$} & \multirow[b]{2}{*}{$\boldsymbol{n}$} & \multicolumn{2}{|c|}{ Threshold Difference (dB), Mean \pm SD } & \multirow{2}{*}{$\begin{array}{c}\text { Symmetry Ratio, } \\
\text { Mean } \pm \text { SD }\end{array}$} \\
\hline & & $4,000 \mathrm{~Hz}-2,000 \mathrm{~Hz}$ & $4,000 \mathrm{~Hz}-8,000 \mathrm{~Hz}$ & \\
\hline \multicolumn{5}{|l|}{ Left Ear } \\
\hline $20 \mathrm{~s}$ & 5,508 & $24.8 \pm 15.6$ & $19.6 \pm 10.6$ & $1.4 \pm 1.1$ \\
\hline $30 \mathrm{~s}$ & 6,074 & $25.6 \pm 14.7$ & $19.8 \pm 10.3$ & $1.5 \pm 1.0$ \\
\hline $40 \mathrm{~s}$ & 13,565 & $28.4 \pm 15.5$ & $19.5 \pm 9.9$ & $1.7 \pm 1.2$ \\
\hline $50 \mathrm{~s}$ & 26,785 & $31.5 \pm 16.2$ & $17.6 \pm 8.6$ & $2.1 \pm 1.4$ \\
\hline $60 \mathrm{~s}$ & 38,484 & $31.8 \pm 16.4$ & $15.8 \pm 7.3$ & $2.3 \pm 1.5$ \\
\hline $70 \mathrm{~s}$ & 15,722 & $28.0 \pm 15.2$ & $13.7 \pm 5.4$ & $2.2 \pm 1.4$ \\
\hline $80 \mathrm{~s}$ & 7,295 & $24.8 \pm 12.9$ & $12.7 \pm 4.5$ & $2.1 \pm 1.2$ \\
\hline $90 \mathrm{~s}$ & 385 & $22.6 \pm 11.3$ & $12.4 \pm 4.3$ & $1.9 \pm 1.0$ \\
\hline 20s-90s & 113,818 & $29.6 \pm 16.0$ & $16.6 \pm 8.3$ & $2.1 \pm 1.4$ \\
\hline \multicolumn{5}{|l|}{ Right Ear } \\
\hline $20 \mathrm{~s}$ & 4,247 & $23.7 \pm 15.1$ & $19.1 \pm 10.3$ & $1.4 \pm 1.0$ \\
\hline $30 \mathrm{~s}$ & 5,133 & $25.0 \pm 14.8$ & $19.6 \pm 10.3$ & $1.4 \pm 1.0$ \\
\hline $40 \mathrm{~s}$ & 12,016 & $28.3 \pm 15.3$ & $19.4 \pm 9.8$ & $1.7 \pm 1.2$ \\
\hline $50 \mathrm{~s}$ & 25,942 & $31.6 \pm 16.2$ & $17.9 \pm 8.8$ & $2.1 \pm 1.4$ \\
\hline $60 \mathrm{~s}$ & 38,221 & $32.4 \pm 16.5$ & $16.2 \pm 7.7$ & $2.3 \pm 1.5$ \\
\hline $70 \mathrm{~s}$ & 15,573 & $28.9 \pm 15.6$ & $14.0 \pm 5.9$ & $2.3 \pm 1.4$ \\
\hline $80 \mathrm{~s}$ & 7,105 & $25.8 \pm 13.5$ & $12.8 \pm 5.1$ & $2.2 \pm 1.2$ \\
\hline $90 \mathrm{~s}$ & 379 & $22.8 \pm 11.0$ & $13.0 \pm 7.7$ & $1.9 \pm 0.9$ \\
\hline 20s-90s & 108,616 & $30.1 \pm 16.1$ & $16.7 \pm 8.4$ & $2.1 \pm 1.4$ \\
\hline
\end{tabular}

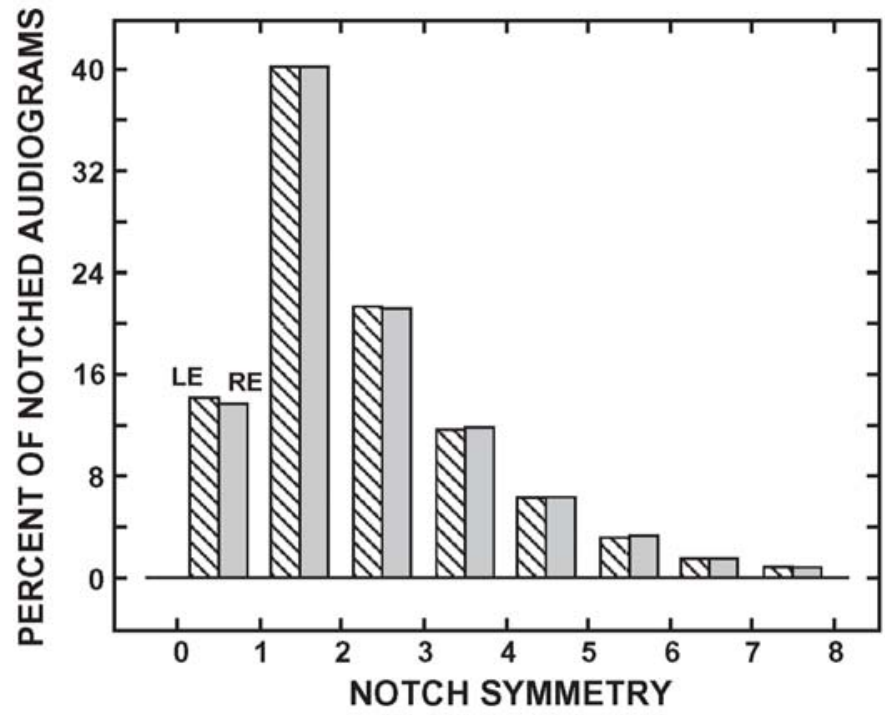

Figure 4.

Histograms of percentage of left ear (LE) (striped) and right ear (RE) (shaded) 4,000 Hz notched audiograms for eight notch symmetries. LE $n=113,818$; RE $n=108,616$. notch depths. Only 16 to 17 percent of the notches were observed at the minimum notch depth of 10.0 to $12.5 \mathrm{~dB}$. Conversely, 83 to 84 percent of the notch depths were $\geq 15.0 \mathrm{~dB}$. The distributions of notch depths maximize in the 15.0 to $17.5 \mathrm{~dB}$ notch depth category with a systematic decrease through the $50.0^{+} \mathrm{dB}$ depth. Although substantially fewer participants were involved in the earlier study of 3,430 veterans, almost identical 4,000 Hz notch depth characteristics were observed for the LEs and REs in that study [28, p. 28: Figure 3].

Second, the distributions of LE and RE notch depths for each of the eight decades were evaluated and are shown in Figure 6. In each age decade, the LE and RE histograms closely correspond, indicating similar notching patterns in the two ears as a function of age. The distributions are skewed for the shallower notch depths in the 20 and 30 yr decades, becoming somewhat rounded through the 40, 50, and 60 yr decades. In the latter three decades, the notch depths again progressively become skewed toward the shallower depths, with fewer and fewer deep notches from the 70 to 90 yr decades. As mentioned earlier, this latter phenomenon probably is 


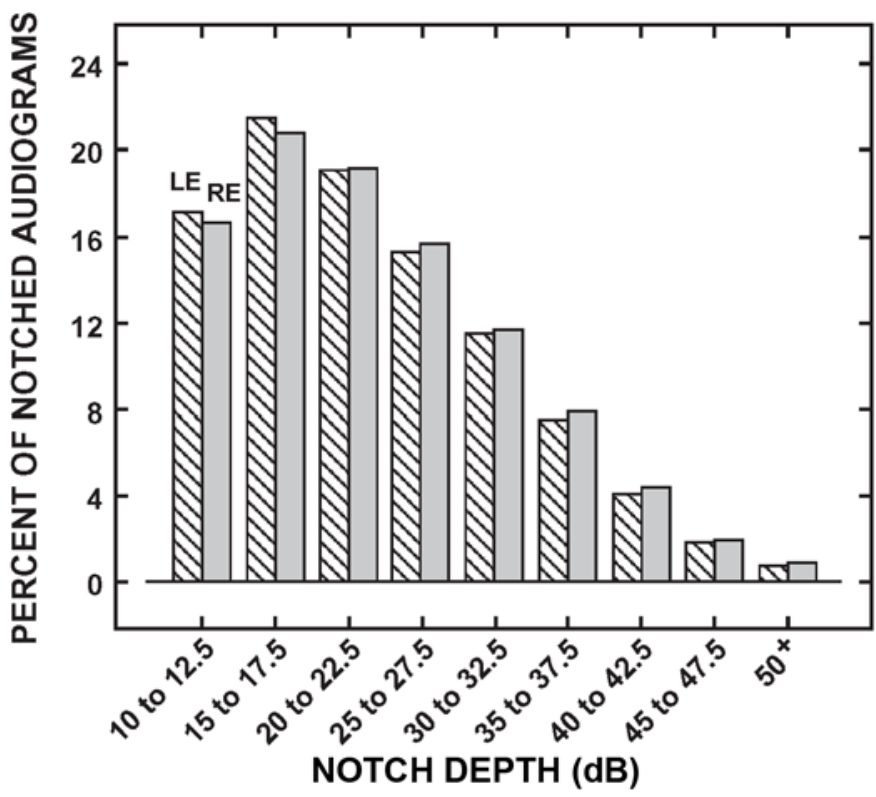

Figure 5.

Histograms of percentage of left ear (LE) (striped) and right ear (RE) (shaded) 4,000 Hz notched audiograms for nine notch depths. LE $n=113,818$; RE $n=108,616$.

related to the threshold at $8,000 \mathrm{~Hz}$ increasingly becoming higher (poorer) as a function of age. Because the thresholds at 4,000 and $8,000 \mathrm{~Hz}$ approximate one another, the definition of a notch is precluded.

Third, the notch depths were studied with respect to the unilateral and bilateral occurrence of the notches. Specifically, the question was, What were the distributions of notch depths for the notches that occurred in a given ear of unilateral notches and the same ear of bilateral notches; i.e., Were the notches in these two notch conditions the same or different? For the 113,818 LE notched audiograms, the mean notch depths were $21.7 \mathrm{~dB}(62,088 \mathrm{LE}$ unilateral) and $24.8 \mathrm{~dB}$ (51,731 LE of a bilateral notch) with SD values of 9.1 and $9.6 \mathrm{~dB}$, respectively. Similarly, for the 108,616 RE notched audiograms, the mean notch depths were $21.7 \mathrm{~dB}(56,884$ $\mathrm{RE}$ of a unilateral notch) and $25.3 \mathrm{~dB}$ (51,731 RE of a bilateral notch) with SD values of 9.0 and $9.8 \mathrm{~dB}$, respectively. In addition to the $\sim 3.5 \mathrm{~dB}$ deeper mean notch depth when the notching was bilateral, the histograms of the RE notch depths of unilateral notches (striped) and bilateral notches (shaded) shown in Figure 7 demonstrate that the distributions of the unilateral and bilateral notch depths were different. (Note: The same plot of LE

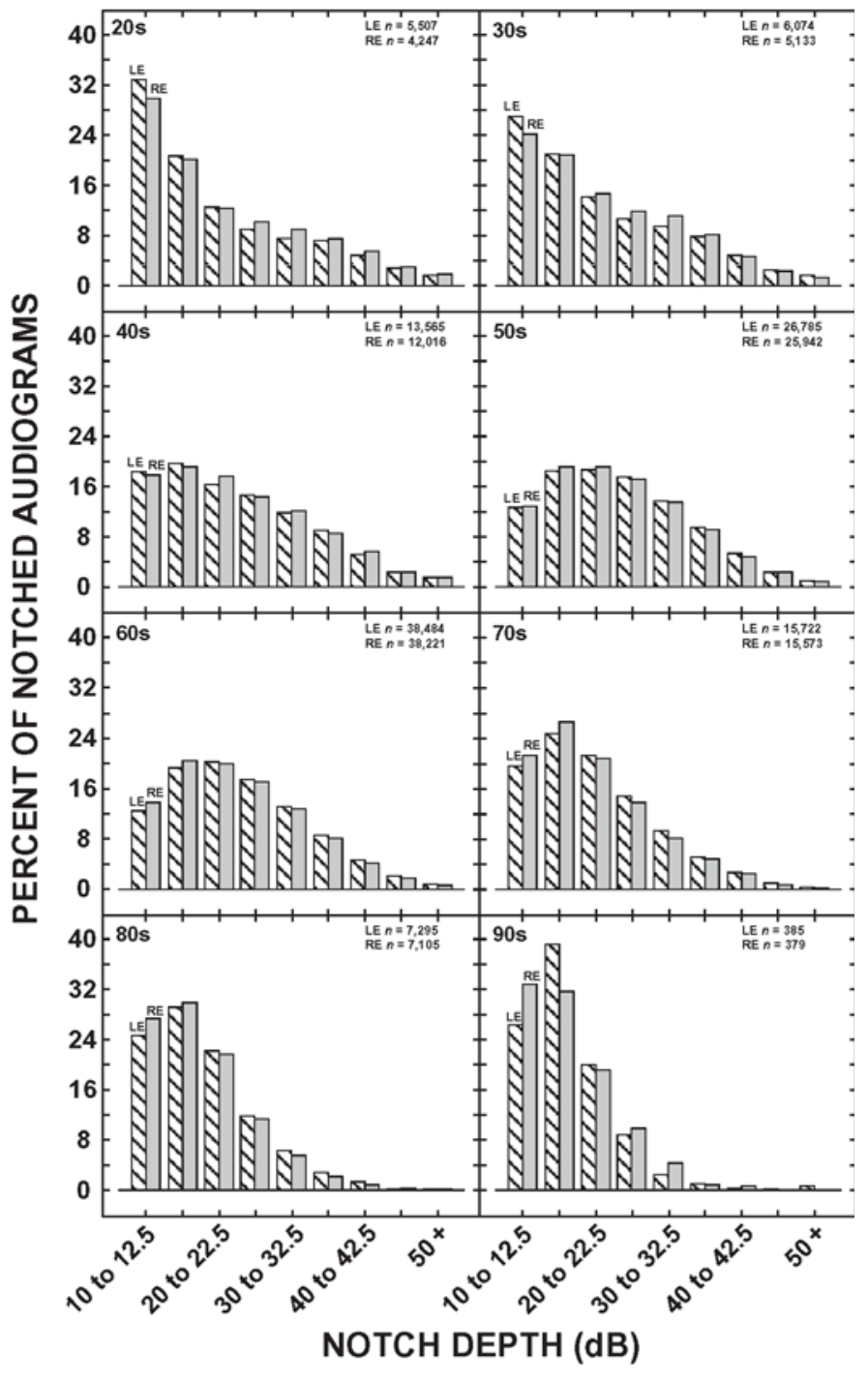

Figure 6.

Histograms for eight age categories of percentage of left ear (LE) (striped) and right ear (RE) (shaded) 4,000 Hz notched audiograms for nine notch depths.

notch depths had similar distributions for the unilateral and bilateral notches.) When the notches were unilateral, 45 percent of the notch depths were 10.0 to $17.5 \mathrm{~dB}$, whereas when the notches occurred in both ears, 30 percent of the notch depths were 10.0 to $17.5 \mathrm{~dB}$. For both the LE and RE, the bilateral notches were more prevalent in the deeper notch depths than were the unilateral notches, which were reflected directly in the previously mentioned mean differences between unilateral and bilateral notches. In general, the bilateral notches are steeper 


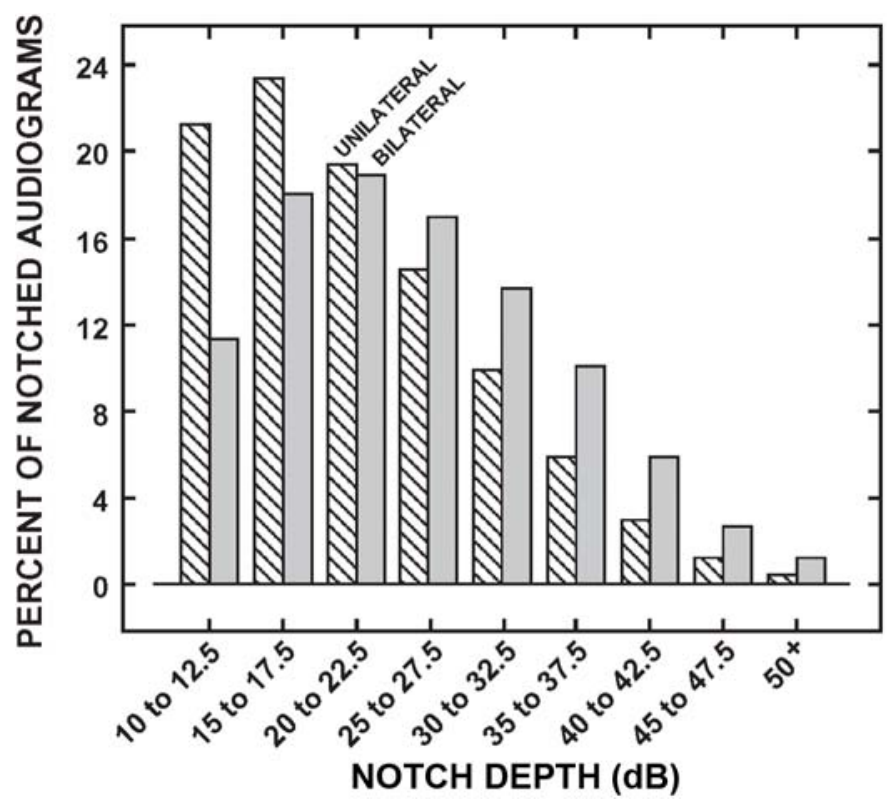

Figure 7.

Histograms of percentage of unilateral right ear (RE) (striped) and bilateral RE (shaded) 4,000 Hz notched audiograms for nine notch depths. Unilateral RE $n=56,885$; bilateral RE $n=51,731$.

or deeper than the unilateral notches, the meaning of which is unclear.

Fourth, of the 51,731 participants with bilateral 4,000 Hz notches, 20,841 (40.3\%) had LE notches that were deeper than the RE notches (LE mean $\pm \mathrm{SD}=29.2 \pm 9.5 \mathrm{~dB}$; RE mean $\pm \mathrm{SD}=21.3 \pm 8.3 \mathrm{~dB}), 23,824(46.1 \%)$ had $\mathrm{RE}$ notches that were deeper than the LE notches (LE mean \pm $\mathrm{SD}=21.4 \pm 8.2 \mathrm{~dB}$; RE mean $\pm \mathrm{SD}=29.5 \pm 9.5 \mathrm{~dB}$ ), and 7,066 (13.7\%) had equivalent notch depths in the two ears (mean $\pm \mathrm{SD}=22.9 \pm 9.1 \mathrm{~dB}$ ). The overall mean notch depth for the $\mathrm{LE}$ was $24.8 \mathrm{~dB}(\mathrm{SD}=9.6 \mathrm{~dB})$ and for the RE was $25.3 \mathrm{~dB}(\mathrm{SD}=9.8 \mathrm{~dB})$. The mean absolute difference between the LE and RE notch depths was $6.9 \mathrm{~dB}$ (SD = $6.2 \mathrm{~dB}$ ). A comparison of the LE and RE notch depths for the 51,731 participants with bilateral 4,000 $\mathrm{Hz}$ notches is illustrated ${ }^{*}$ in Figure 8. Interestingly, calculations with the linear regression equation indicate that only around a notch depth of $25 \mathrm{~dB}$ is there a one-to-one relation between the notch depths for the two ears. Below $25 \mathrm{~dB}$, the RE notch depth is deeper than the LE notch depth; e.g., at an LE notch depth of $10 \mathrm{~dB}$, the RE notch depth is $17.1 \mathrm{~dB}$. Conversely, above $25 \mathrm{~dB}$, the $\mathrm{LE}$ notch depth is deeper than the RE notch depth; e.g., at an LE notch depth of $60 \mathrm{~dB}$, the RE notch depth is only $44.9 \mathrm{~dB}$. These data indicate that when

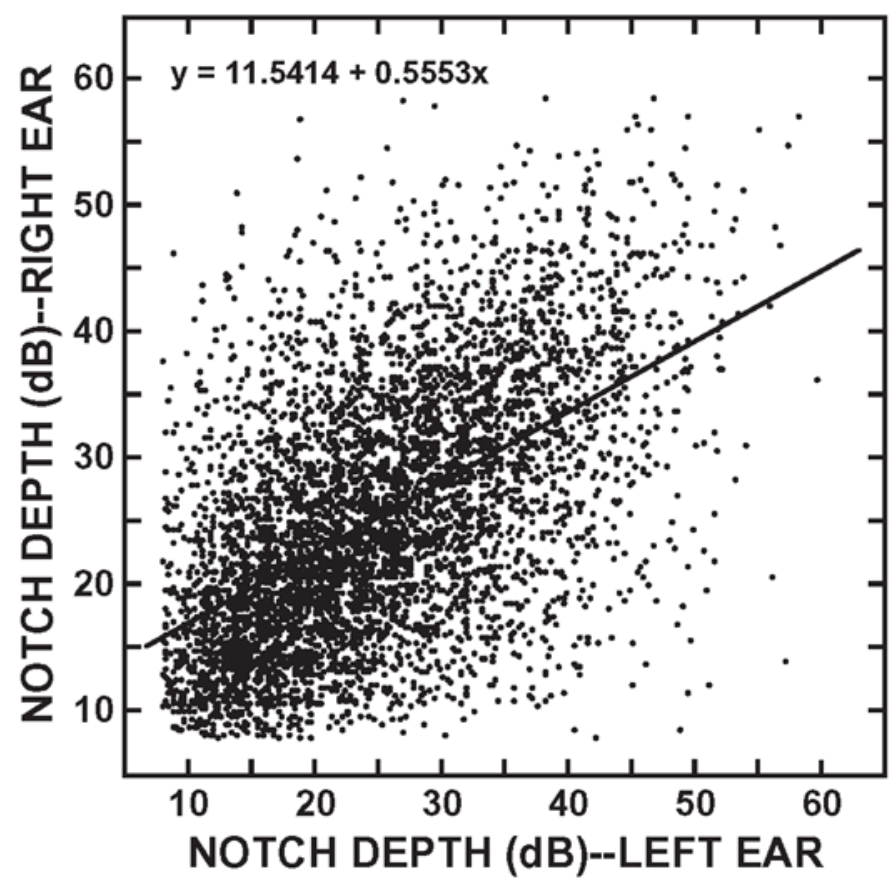

Figure 8.

Bivariate illustration of notch depth (decibels) for right ear (ordinate) and left ear (abscissa) of 51,731 individuals with bilateral $4,000 \mathrm{~Hz}$ notches. For graphic clarity, (1) data points were jittered randomly using additive algorithm from $-2.4 \mathrm{~dB}$ to $2.4 \mathrm{~dB}$ in $0.05 \mathrm{~dB}$ steps, and (2) only every 10th data point is shown. Linear regression reflects 51,731 notch pairs $\left(R^{2}=0.3\right)$.

the $4,000 \mathrm{~Hz}$ notch is bilateral, a different dynamic is operating in the two ears. When the notch is shallow, the RE notch tends to be deeper than the LE notch. When the notch is deep, the LE notch tends to be deeper than the RE notch.

\section{Group 1 Mean Audiograms}

The mean audiograms for the REs are shown for the eight decades in Figures 9 and 10. In each panel of both figures, the number of participants is indicated. In Figure 9, three mean audiograms are depicted in each panel, including

\footnotetext{
*Because plotting 51,731 datum points resulted in a black blob, a random sample of 5,173 datum points was used to illustrate the relationship between ears. The data were jittered randomly using an additive algorithm from -1.25 to 1.25 in 0.05 steps. The linear regression shown in the figure, however, is based on the 51,731 individuals; a regression based on the 5,173 individuals provided essentially the same equation, thus ensuring that the plotted sample reflected accurately the full sample.
} 


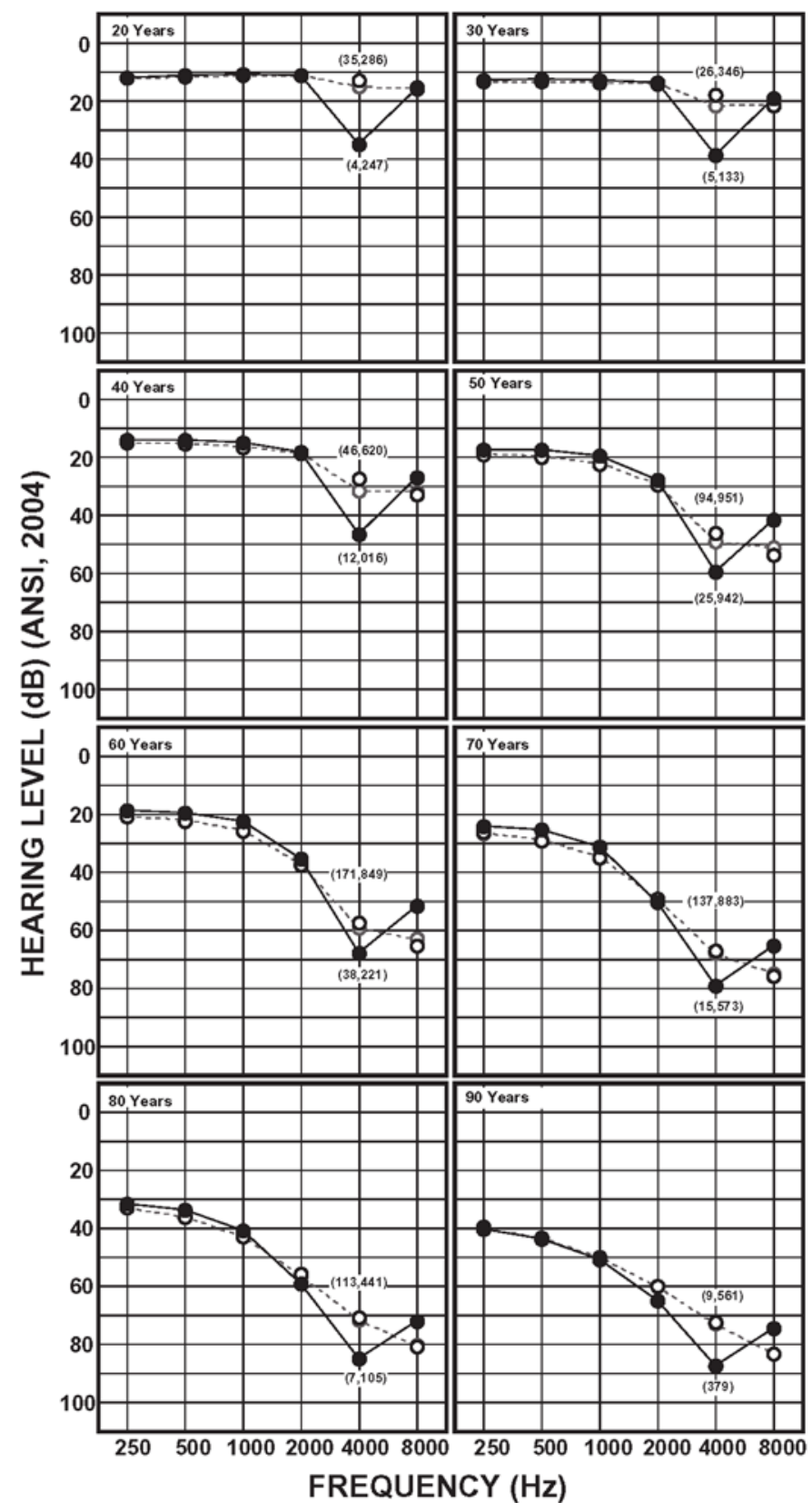

Figure 9.

Mean right ear notched (filled circles) and unnotched (black open circles) audiograms for eight age groups. Gray open circles are average audiogram for the two groups in each panel. Numbers in parentheses indicate number of participants in each group. Hearing level as defined by American National Standards Institute (ANSI) [32].

notched audiograms (filled circles), unnotched audiograms (black open circles), and mean audiogram for notched and unnotched combined (gray open circles).

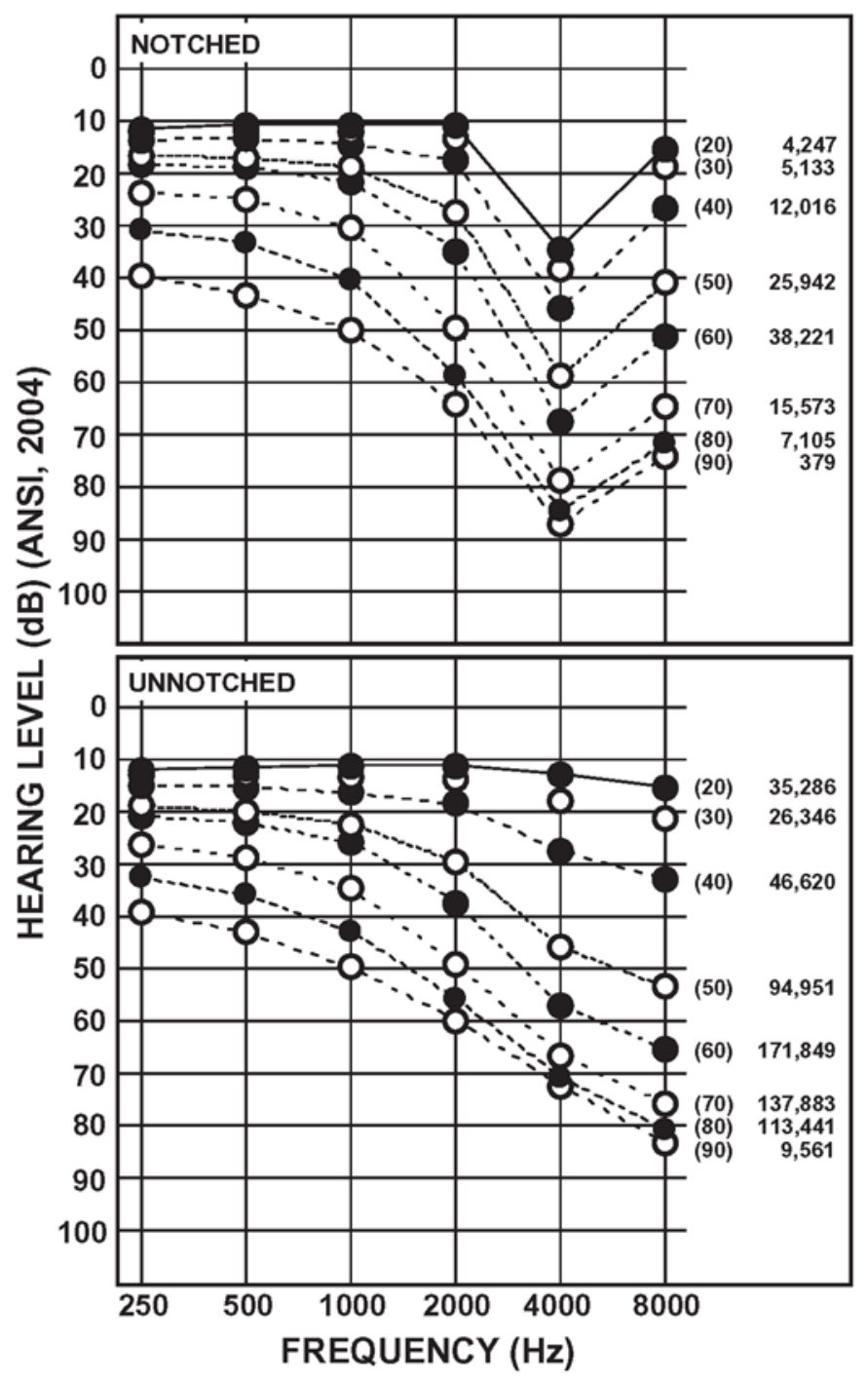

Figure 10.

Mean right ear notched and unnotched audiograms for eight age groups (indicated in parentheses). Adjacent numbers are number of participants in each group. Notched $n=108,616$; unnotched $n=625,937$. Hearing level as defined by American National Standards Institute (ANSI) [32].

Three relations are noteworthy in Figure 9. First, for each age group, the pure-tone thresholds at 250 to $2,000 \mathrm{~Hz}$ are essentially the same for the notched and unnotched groups. The equal mean $2,000 \mathrm{~Hz}$ thresholds for the notched and unnotched groups substantiate the appropriateness of using the $2,000 \mathrm{~Hz}$ threshold as the lower frequency anchor in the definition of the high-frequency audiometric notch. Second, in all age groups except the 
20s, the mean threshold at $8,000 \mathrm{~Hz}$ for the notched group is lower (better) than the mean threshold at $8,000 \mathrm{~Hz}$ for the unnotched group. Perhaps this difference between groups at 8,000 $\mathrm{Hz}$ reflects the different pathophysiological processes involved with notched and unnotched audiograms or with noise-induced hearing loss and agerelated hearing loss [44-45]. Finally, because the notch is present in a minority of participants in all age groups, the effect of the notched audiograms on the overall mean audiogram is minimal, with the mean audiograms not reflecting the presence of a $4,000 \mathrm{~Hz}$ notch.

The mean RE audiograms in Figure 10 enable comparisons across ages of the notched $(n=108,616,14.6 \%)$ and unnotched ( $n=635,937,85.4 \%$ ) audiograms. As in the earlier Wilson article [28], the range of mean thresholds across the age decades is substantially less in the low frequencies than in the high frequencies. For both the notched and unnotched RE audiograms, the range at $250 \mathrm{~Hz}$ was $28 \mathrm{~dB}$, increasing at $8,000 \mathrm{~Hz}$ to $59 \mathrm{~dB}$ (notched) and $68 \mathrm{~dB}$ (unnotched). These differences translate into rates of change over the $70 \mathrm{yr}$ span of $0.4 \mathrm{~dB} / \mathrm{yr}$ at $250 \mathrm{~Hz}$ and 0.8 to $1.0 \mathrm{~dB} / \mathrm{yr}$ at $8,000 \mathrm{~Hz}$. These differences across ages have been noted in several previous studies [38,46-50]. It is interesting in these cross-sectional data that the biggest threshold differences occurred in the two highest frequencies between the 40 and $50 \mathrm{yr}$ decades, especially in the unnotched group. A similar observation can be made in the Wilson data [28, p. 25: Figure 1].

\section{Group 2 (3,000, 4,000, and 6,000 Hz Data)}

The mean audiograms for the LE and RE of the 539,932 participants included in the analyses of the 3,000, 4,000, and 6,000 Hz notch data are listed in Table 5 . Again, the mean audiograms reflect mild-to-moderate, high-frequency sensorineural hearing losses with mean PTAs 28.9 and 28.0 dB HL (SD = 16.6 and $16.4 \mathrm{~dB}$ ) for the LE and RE, respectively, with corresponding HFPTAs of 39.7 and $38.2 \mathrm{~dB}$ HL (SD = 19.0 and $18.9 \mathrm{~dB}$ ). As with the earlier threshold data in Table 1, of which the present data are a subset, the mean threshold differences at 250, 500 , and $1,000 \mathrm{~Hz}$ are $<0.5 \mathrm{~dB}$, with the mean RE thresholds in the 2,000 to 6,000 $\mathrm{Hz}$ range about $2 \mathrm{~dB}$ lower (better) than the mean LE thresholds at those frequencies. At $8,000 \mathrm{~Hz}$, the mean RE threshold was $1.2 \mathrm{~dB}$ lower than the mean LE threshold.

\section{Group 2 Notch Prevalence}

The audiogram pairs were analyzed for notches at $3,000,4,000$, and $6,000 \mathrm{~Hz}$ using the $10 \mathrm{~dB}$ criteria that was used with group 1's $4,000 \mathrm{~Hz}$ notch data. The majority of the 539,932 audiogram pairs (352,537 or $65.3 \%)$ did not have a notch in the air-conduction audiogram of either ear at 3,000, 4,000, or $6,000 \mathrm{~Hz}$. Of the remaining 187,395 audiogram pairs, 120,817 (22.4\%) were unilateral notches at one or more of the three notch frequencies (62,894 LEs, 11.6\%; 57,923 REs, 10.7\%) and 66,578 (12.3\%) were bilateral notches at one or more of the three notch frequencies. Considering unilateral and bilateral notches collectively, 410,460 LEs (76.0\%) and 415,431 REs (76.9\%) did not have a notch at any of the three notch frequencies; conversely, 129,472 LEs (24.0\%) and 124,501 REs (23.1\%) had a notch minimally at one of the notch frequencies. Notches were measurable (1) at one frequency in 104,763 LEs (19.4\%) and 101,470 REs (18.8\%), (2) at two frequencies in 22,461 LEs (4.2\%) and 21,170 REs (3.9\%), and (3) at all three frequencies in 2,248 LEs (0.4\%) and 1,861 REs (0.3\%).

The data in Figure 11 give the percentage of participants in each age decade who had unnotched (squares) and notched audiograms (pluses). For inclusion in the notched category, a notch was required at one of the three notch frequencies in either ear; thus, the notched category included three single notches $(3,000,4,000$, or $6,000 \mathrm{~Hz})$ and four multiple notch combinations $(3,000$ and $4,000 \mathrm{~Hz} ; 3,000$ and 6,000 Hz; 4,000 and 6,000 Hz; and 3,000, 4,000, and $6,000 \mathrm{~Hz}$ ). As previously mentioned, overall 65.3 percent of the audiograms were unnotched and 34.7 percent were

Table 5.

Mean \pm standard deviation left ear (LE) and right ear (RE) pure-tone air-conduction thresholds (decibels hearing level [32]) from 539,932 individuals between ages of 20 and $90+$ yr.

\begin{tabular}{ccccccccc}
\hline \multirow{2}{*}{ Ear } & \multicolumn{7}{c}{ Frequency (Hz) } \\
\cline { 2 - 9 } & $\mathbf{2 5 0}$ & $\mathbf{5 0 0}$ & $\mathbf{1 , 0 0 0}$ & $\mathbf{2 , 0 0 0}$ & $\mathbf{3 , 0 0 0}$ & $\mathbf{4 , 0 0 0}$ & $\mathbf{6 , 0 0 0}$ & $\mathbf{8 , 0 0 0}$ \\
\hline LE & $21.4 \pm 13.9$ & $22.7 \pm 15.0$ & $26.4 \pm 17.3$ & $37.6 \pm 22.4$ & $49.1 \pm 23.7$ & $55.2 \pm 24.3$ & $57.4 \pm 25.2$ & $58.7 \pm 26.7$ \\
RE & $21.3 \pm 13.7$ & $22.5 \pm 14.8$ & $26.0 \pm 16.9$ & $35.4 \pm 21.9$ & $46.6 \pm 23.9$ & $53.0 \pm 24.8$ & $55.6 \pm 25.7$ & $57.5 \pm 27.3$ \\
\hline Difference (RE-LE) & -0.1 & -0.2 & -0.4 & -2.2 & -2.5 & -2.2 & -1.8 & -1.2 \\
\hline \hline
\end{tabular}




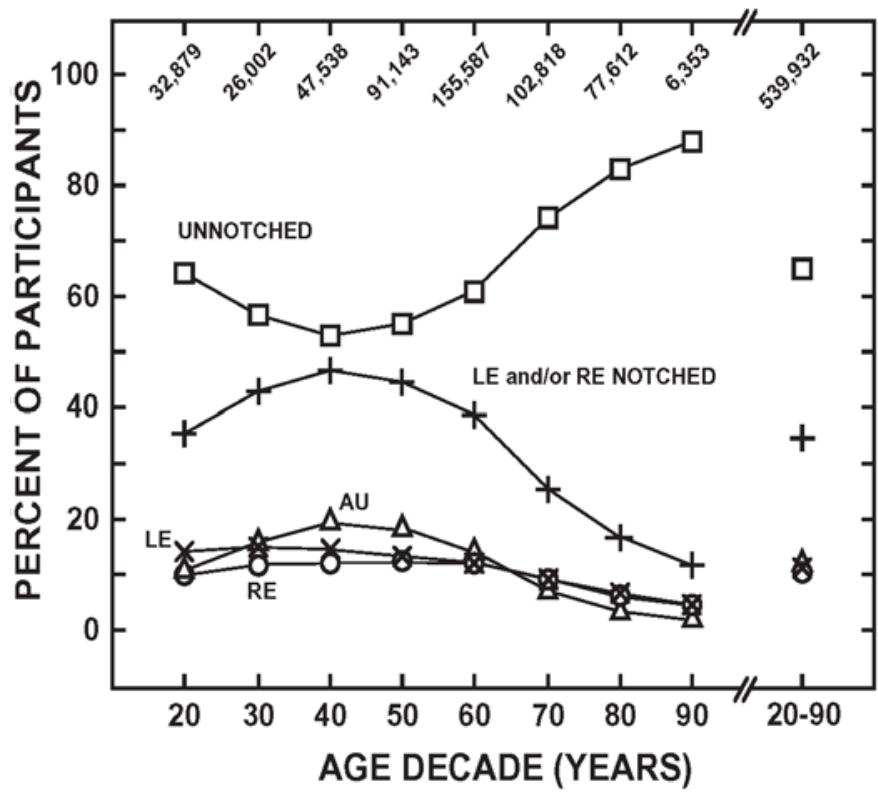

Figure 11.

Percentage of participants in each age group with no audiometric notch at 3,000, 4,000, and/or $6,000 \mathrm{~Hz}$ in either ear (squares) or with one or more notches in either ear at 3,000, 4,000 , and/or $6,000 \mathrm{~Hz}$ (pluses) are shown. Notched category is parsed into three subgroups: unilateral left ear (LE) notches (Xs), unilateral right ear (RE) notches (circles), and bilateral notches (AU, triangles). Number of participants in each age group is indicated at top of graph.

notched at a minimum of one frequency. As a function of age in Figure 11, the percentage of participants with unnotched audiograms is characterized by a concave function, just as was observed with the $4,000 \mathrm{~Hz}$ notch data in Figure 2. The inclusion of 3,000 and $6,000 \mathrm{~Hz}$ in the notch frequency category differentially but systematically affected the percentage of unnotched audiograms in each age decade. From Figure 11, the minimum percentage of unnotched audiograms was in the 40 yr decade (53.1\%) and the maximum percentage of unnotched audiograms was in the $90 \mathrm{yr}$ decade (88.0\%). Because the data in Figure $\mathbf{1 1}$ are normalized, the notched data are the inverse of the unnotched data, with the maximum percentage of notched audiograms in the $40 \mathrm{yr}$ decade $(46.9 \%)$ and the minimum in the $90 \mathrm{yr}$ decade (12.0\%). When the unnotched data in Figures $\mathbf{2}$ and $\mathbf{1 1}$ are compared, with three notch frequencies included in the criteria, the percentage of participants in each age decade with notched audiograms increased on average by $\sim 12$ percent, with the larger increases in the lower age decades ( 16\%) than in the higher age decades ( $6 \%)$. The notched audiograms in Figure $\mathbf{1 1}$ are subdivided into the percentage of participants with LE notches (Xs), RE notches (circles), and bilateral notches (AU, triangles). Although in some age decades the percentage of bilateral notches is greater than the percentage of LE or RE unilateral notches, collectively, the percentage of bilateral notches is about equivalent to the percentage of LE or RE unilateral notches, with the three measures mostly fluctuating between 10 and 20 percent of the participants for the various decade intervals.

For a given ear of a participant in group 2, notches in the audiogram occurred at one frequency or a combination of the three notch frequencies. The percentage of participants with RE unilateral or bilateral notched audiograms are shown for the three notch frequencies in Figure 12 at each of the decade intervals; although not illustrated, LE plots of the same data parameters were essentially identical. The data for the same LE conditions are listed in the lower portions of the two sections in Table 6, which includes a complete listing of the raw prevalence data and the corresponding prevalence percentages for the LE, respectively. In both panels of Table 6, the number and corresponding percentage of LEs

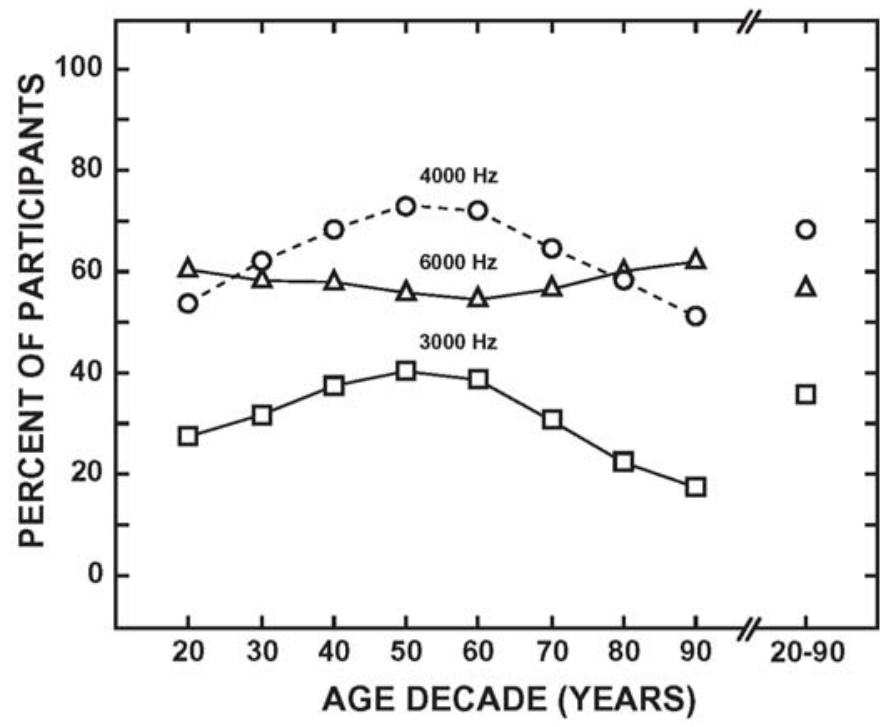

Figure 12.

Percentage of participants with right ear notched audiograms in each age group that had single notches or notches in combination with other frequencies at 3,000 (squares), 4,000 (circles), and $6,000 \mathrm{~Hz}$ (triangles) are shown. 
Table 6.

Number of left ears (LEs) in each age category that were unnotched or notched and that had notches at one, two, or three notch frequencies. Total for each notch frequency is sum of notches for particular notch frequency. Mean percentage of unnotched and notched LE audiograms in each age category and mean percentage of notched audiograms represented by various notched categories.

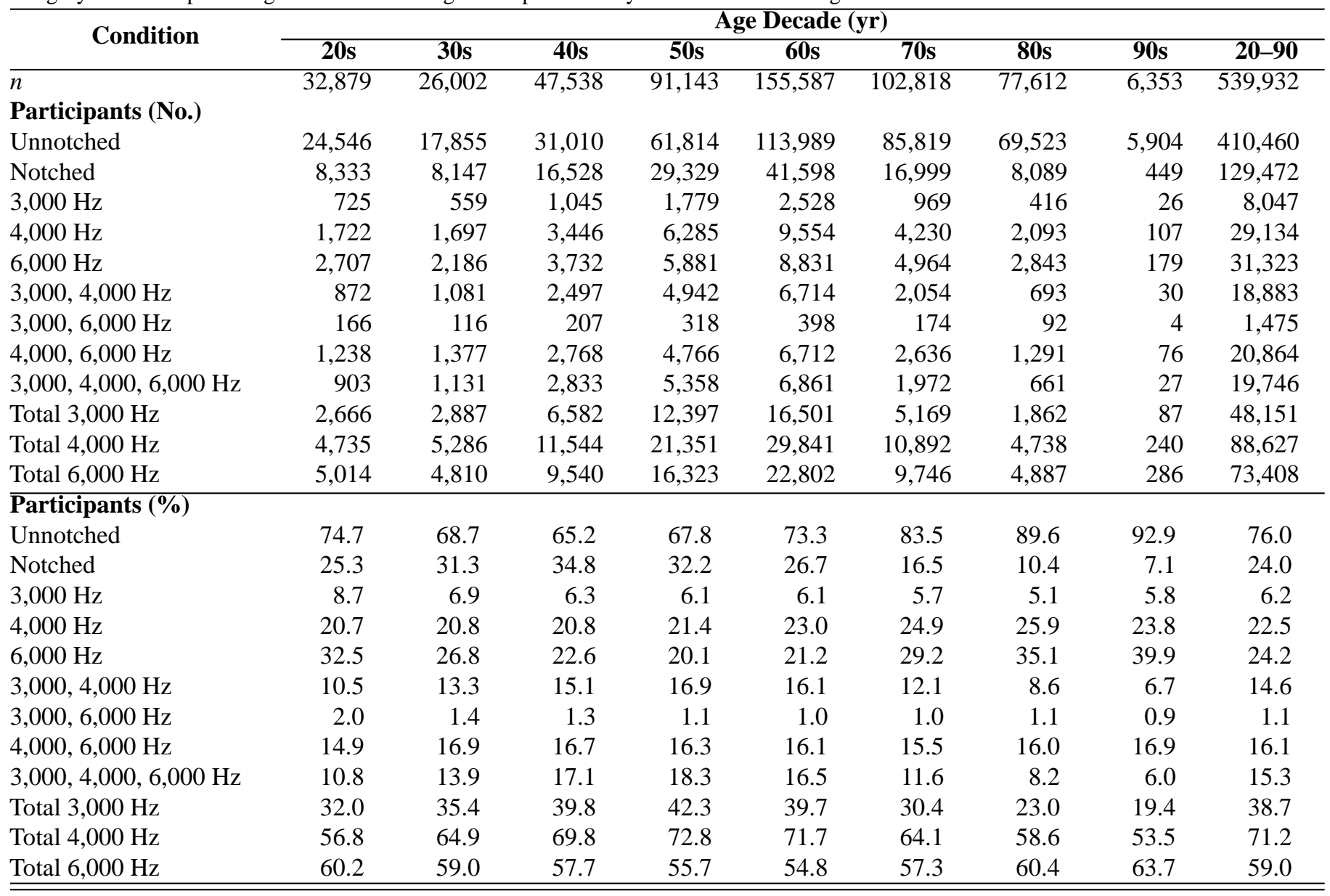

with single notches and multiple notch combinations are listed for each of the eight age decades and overall (20-90 $y r)$. The RE percentage data for the same seven notch combinations are plotted in Figure 13; although not shown, the same plot of the LE notch data was almost identical to the RE data, the exception being the slightly higher overall prevalence of notches in the LE than in the RE.

Several observations are notable from the data in Table 6 and Figures 12 and 13. First, in Figure 12 (RE) and the lower panel of Table 6 (LE), overall $4,000 \mathrm{~Hz}$ notches are the most common with $6,000 \mathrm{~Hz}$ notches the second most common, followed at a distant third by $3,000 \mathrm{~Hz}$ notches. There are differences, however, among the age decades. Second, 4,000 Hz notches are the most prevalent in the 40 to $70 \mathrm{yr}$ decades, $6,000 \mathrm{~Hz}$ notches are the most prevalent in the 20 and $90 \mathrm{yr}$ decades, and there is equal prevalence in the 30 and $80 \mathrm{yr}$ decades. Third, for the LE and RE, the prevalence of both the 3,000 and $4,000 \mathrm{~Hz}$ notches increases from the 20 to the 50 to $60 \mathrm{yr}$ decades, after which there is a steady decline to the $90 \mathrm{yr}$ decade. The increase in the earlier years suggests the cumulative effects of continued exposure to whatever the causal agent is, whereas the decrease in the later years is probably related to the $8,000 \mathrm{~Hz}$ threshold increasingly lowered (becoming poorer) owing to various aging factors. As suggested earlier in this article and others, because the $8,000 \mathrm{~Hz}$ threshold is found at increasingly higher HLs with increasing age, the requirements for a notch dissolve from $\geq 10 \mathrm{~dB}$ to $<0 \mathrm{~dB}$. Interestingly, the prevalence of the $6,000 \mathrm{~Hz}$ notch is somewhat stable across the age decades for both ears (Figure 12). Fourth, considering the various combinations 


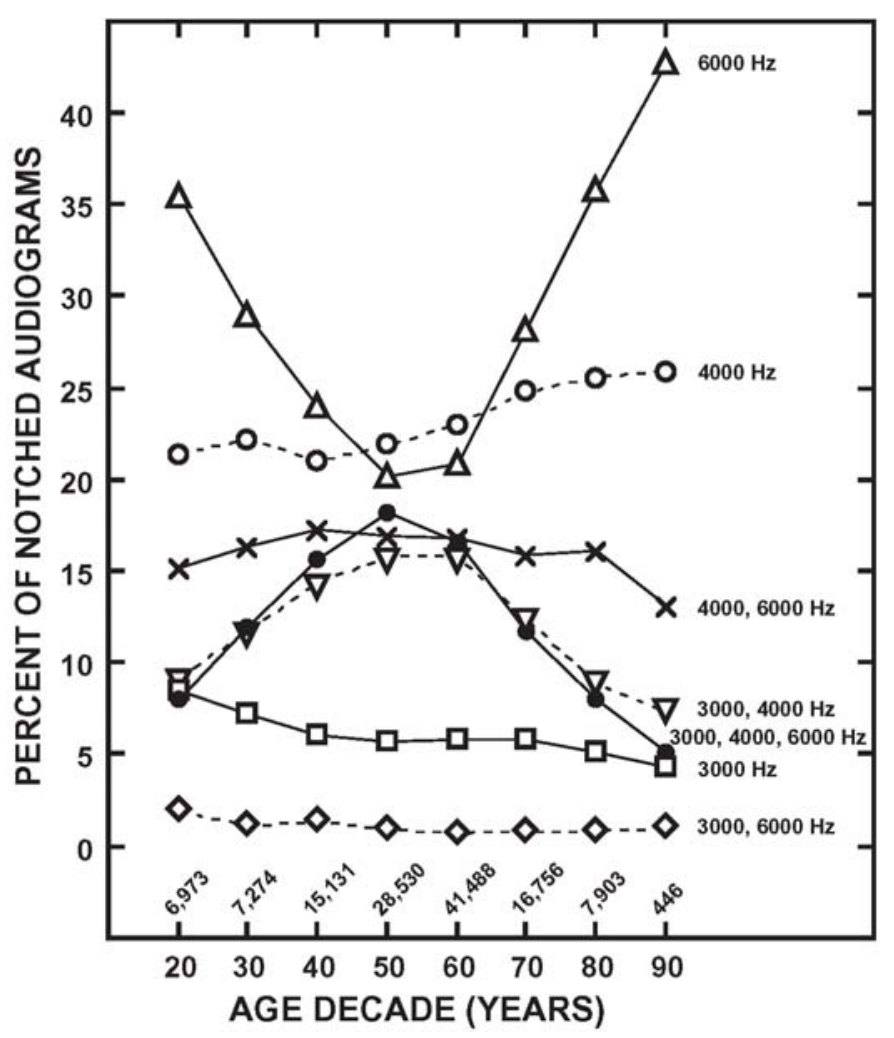

Figure 13.

Percentage of right ear in each age group that had one of seven combinations of $3,000,4,000$, and/or $6,000 \mathrm{~Hz}$ audiometric notch are shown. Notches are at $3,000 \mathrm{~Hz}$ only (squares); 4,000 Hz only (open circles); $6,000 \mathrm{~Hz}$ only (triangles); 3,000 and 4,000 Hz only (inverted triangles); 3,000 and $6,000 \mathrm{~Hz}$ only (diamonds); 4,000 and $6,000 \mathrm{~Hz}$ only (Xs); and $3,000,4,000$, and $6,000 \mathrm{~Hz}$ (filled circles). Number of participants in each age group is indicated at bottom of graph.

of single notches and multiple notches (Figure 13, RE; and Table 6, LE), single notches at 4,000 and $6,000 \mathrm{~Hz}$ are essentially equal in overall prevalence and are the most prevalent notch frequencies (22\%-24\%). The second group of most prevalent notches (14\%-16\%) includes the 3,000 and 4,000 $\mathrm{Hz}$ multiple notch; the 4,000 and 6,000 Hz multiple notch; and the 3,000, 4,000, and 6,000 Hz multiple notch. The least common notches were the $3,000 \mathrm{~Hz}$ single notch (5\%-6\%) and the 3,000 and 6,000 $\mathrm{Hz}$ multiple notch (1\%-2\%).

Finally regarding the prevalence of 3,000, 4,000, and $6,000 \mathrm{~Hz}$ notches, the 63 notch combinations that were the product of the three notch frequencies and the two ears were examined. The data are presented in Table 7, in which the notch frequency/ear is coded in the first six columns with the number of participants in each category and corresponding percentage of the 187,395 participants listed in the final two columns of the table. The data are sorted from the most prevalent to the least prevalent. The " 1 " in each row designates the frequency or frequencies at which a notch occurred. For example, the data in the 1st row indicate that 19,960 (10.65\%) only had a notch in the $\mathrm{LE}$ at $6,000 \mathrm{~Hz}$ with no notch in the RE. The data in the 13th row indicate that 5,056 participants (2.70\%) had a notch in the $\mathrm{LE}$ at $4,000 \mathrm{~Hz}$ and a notch in the RE at $4,000 \mathrm{~Hz}$. Interestingly, the most prevalent notches were unilateral. The data in the first eight rows represent only unilateral notches, with the first four rows representing single frequency notches (36.4\% of all notches) and the second four rows representing double frequency combination notches (16.6\% of all notches). The most prevalent notch was $6,000 \mathrm{~Hz}$ in the $\mathrm{LE}$, followed by $6,000 \mathrm{~Hz}$ in the RE, $4,000 \mathrm{~Hz}$ in the $\mathrm{LE}$, and $4,000 \mathrm{~Hz}$ in the RE. The most prevalent notch combination was 4,000 and $6,000 \mathrm{~Hz}$ in the LE, with no notch in the RE followed by the same combination in the RE with no notch in the LE. The 3,000, 4,000, and 6,000 Hz bilateral notch combination was 12 th on the list ( $n=5,241$ or $2.8 \%)$. The least prevalent notch combination (row 63) was 3,000 and $6,000 \mathrm{~Hz}$ in both ears ( $n=37$ or $0.02 \%)$. (Note: These data are listed by age decade in the Appendix, available online only.)

\section{Group 2 Notch Depths}

The mean notch depths from the 187,395 participants with at least one notch were essentially identical in the two ears. The mean values were $3,000 \mathrm{~Hz}$ ( $\mathrm{LE}$, mean $\pm \mathrm{SD}=$ $21.1 \pm 8.6 \mathrm{~dB}$; RE, mean $\pm \mathrm{SD}=21.1 \pm 8.6 \mathrm{~dB}), 4,000 \mathrm{~Hz}$ $(\mathrm{LE}$, mean $\pm \mathrm{SD}=23.6 \pm 9.6 \mathrm{~dB}$; RE, mean $\pm \mathrm{SD}=23.9 \pm$ $9.7 \mathrm{~dB}$ ), and 6,000 $\mathrm{Hz}$ (LE, mean $\pm \mathrm{SD}=22.4 \pm 9.2 \mathrm{~dB}$; $\mathrm{RE}$, mean $\pm \mathrm{SD}=22.7 \pm 9.4 \mathrm{~dB}$ ). Overall, the mean notch depths for bilateral notches $(23.5 \mathrm{~dB})$ were slightly deeper than the unilateral notches $(21.0 \mathrm{~dB})$. At 3,000 and $4,000 \mathrm{~Hz}$, the bilateral notches were 3.1 to $3.5 \mathrm{~dB}$ deeper than the unilateral notches but only 0.7 to $1.2 \mathrm{~dB}$ deeper at 6,000 Hz. The histograms in Figure 14 depict the percentage of LE and RE notched audiograms for the three notch frequencies according to the notch depths (in decibels). The distributions by ear and by notch frequency closely approximate one another. The majority of notch depths are in the 10.0 to $27.5 \mathrm{~dB}$ range, with the notch depth modes at the 15.0 to $17.5 \mathrm{~dB}$ range. It is tempting to speculate that the 
JRRD, Volume 50, Number 1, 2013

Table 7.

Number and percentage of 187,395 participants for each of 63 notch configurations. Data are ranked according to prevalence. Notch frequency is indicated by " 1 " in ear/frequency column.

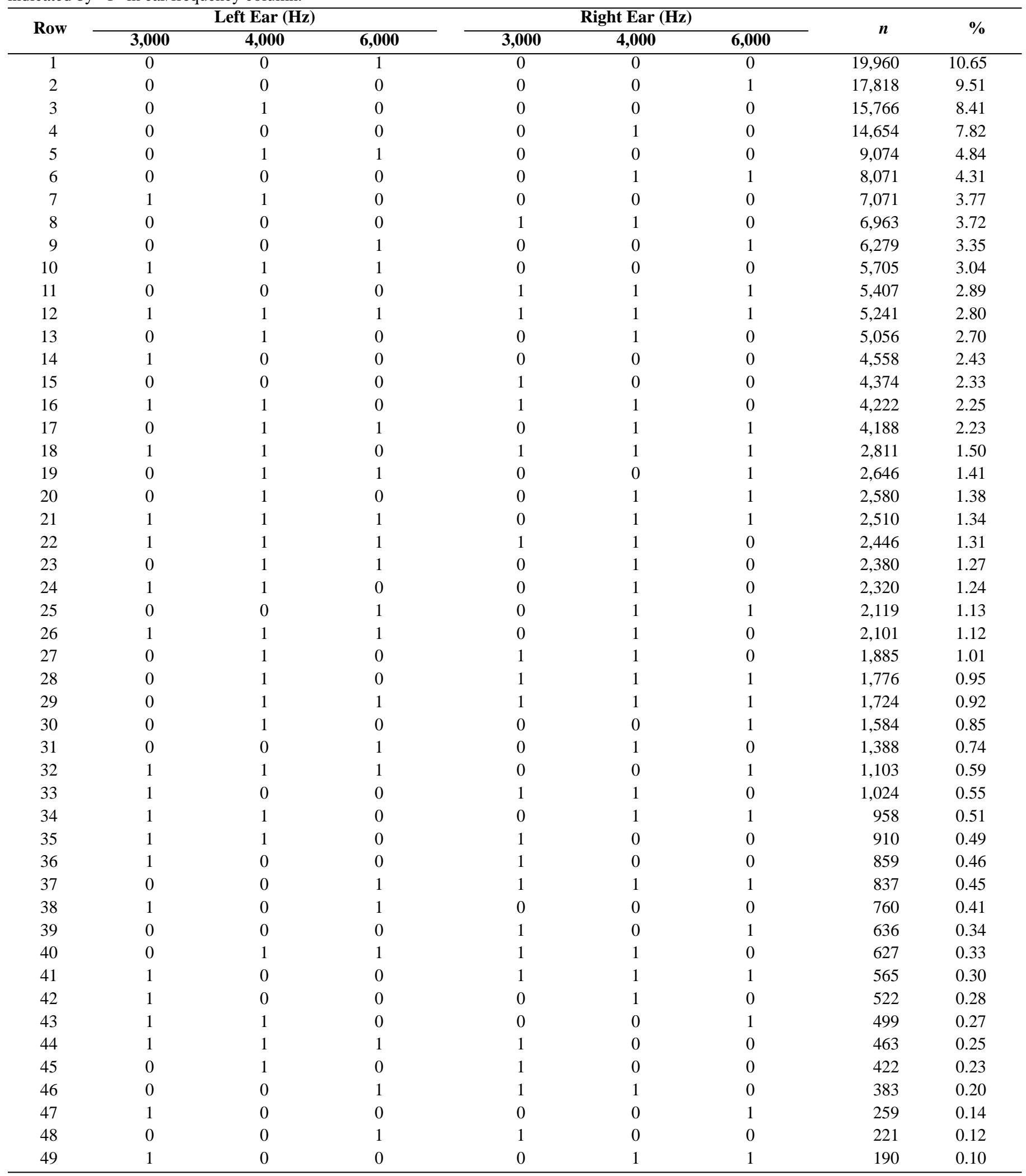


Table 7. (cont)

Number and percentage of 187,395 participants for each of 63 notch configurations. Data are ranked according to prevalence. Notch frequency is indicated by “ 1 ” in ear/frequency column.

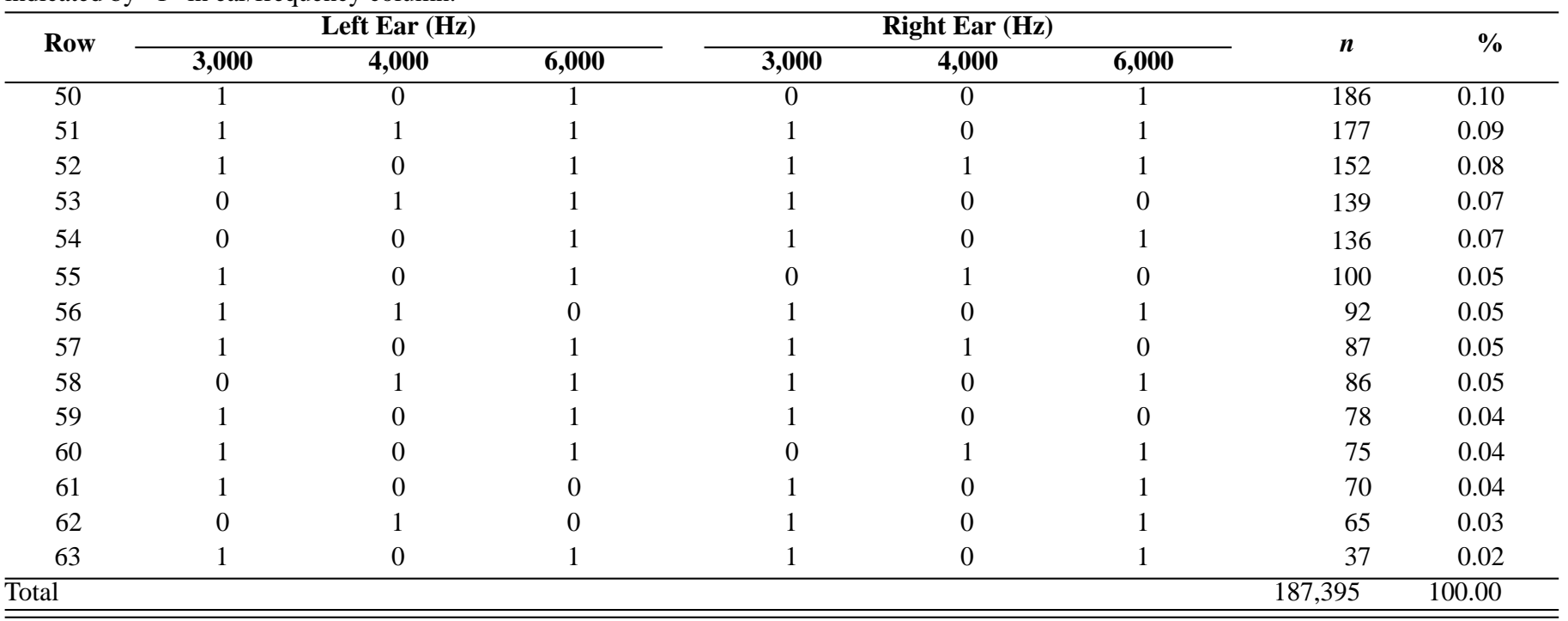

different depths/widths of these notches reflect the combined influences of different magnitudes/durations of noise exposure and individual susceptibility to acoustic trauma. Without a direct cause and effect link, however, speculation is just that, speculation.

\section{Group 2 Mean Audiograms}

The mean audiograms for the RE are shown for the eight decades in Figures 15 and 16. In each panel of both figures, the number of participants is indicated. As presented earlier with the group 1 data, three mean audiograms are depicted in each panel of Figure 15, including notched audiograms (filled circles), unnotched audiograms (black open circles), and mean audiograms (gray open circles). As with the $4,000 \mathrm{~Hz}$ data in Figure 9, the following three relations are noteworthy in Figure 15 (again, the data in Figure 15 are a subset of the data in Figure 9): (1) the puretone thresholds at 250 to $2,000 \mathrm{~Hz}$ are essentially the same for the notched and unnotched groups; (2) in all age groups except the 20s, the mean threshold at $8,000 \mathrm{~Hz}$ for the notched group is lower (better) than the mean threshold at $8,000 \mathrm{~Hz}$ for the unnotched group; and (3) the effect of the notched audiograms on the overall mean audiogram is minimal, with the mean audiograms not reflecting the presence of a notch. Figure 16 shows the mean 3,000, 4,000, and $6,000 \mathrm{~Hz}$ notched $(n=124,501,23.1 \%)$ and unnotched $(n=$ 415,431, 76.9\%) RE audiograms for the eight decade groups. Again, the data are very similar to the data shown

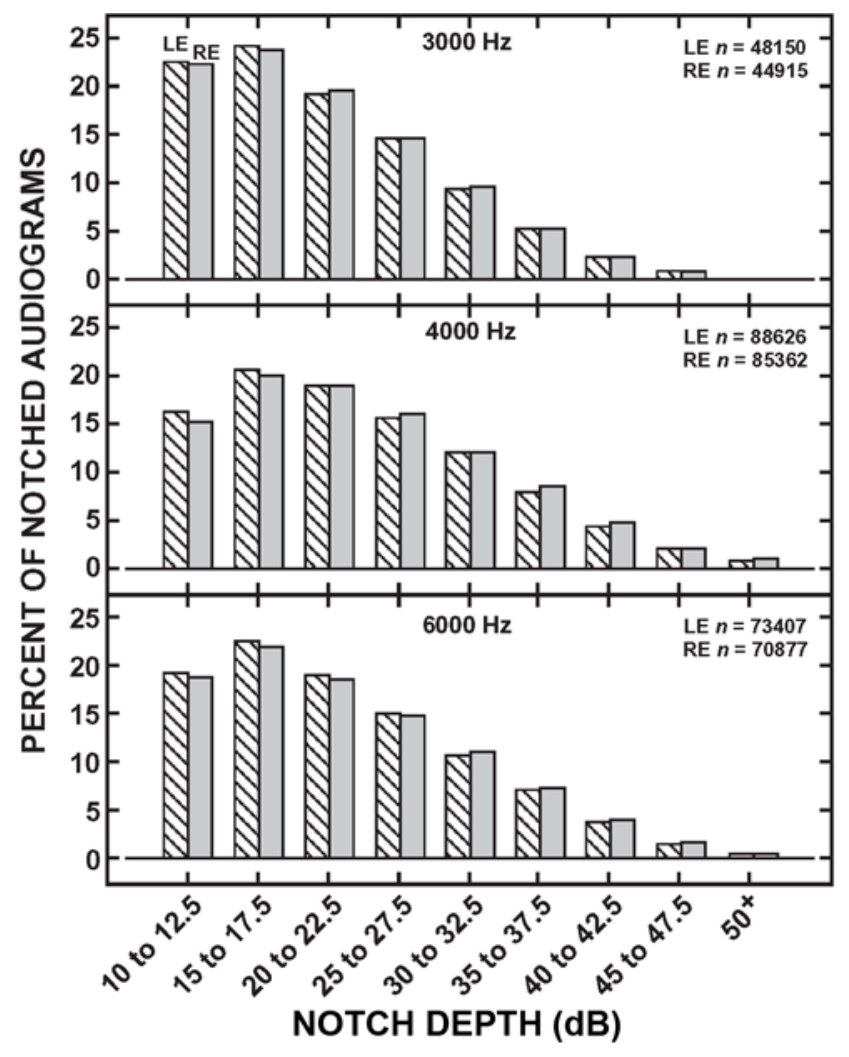

Figure 14.

Histograms of percentage of left ear (LE) (striped) and right ear (RE) (shaded) notched audiograms at $3,000,4,000$, and $6,000 \mathrm{~Hz}$ for nine notch depths. 


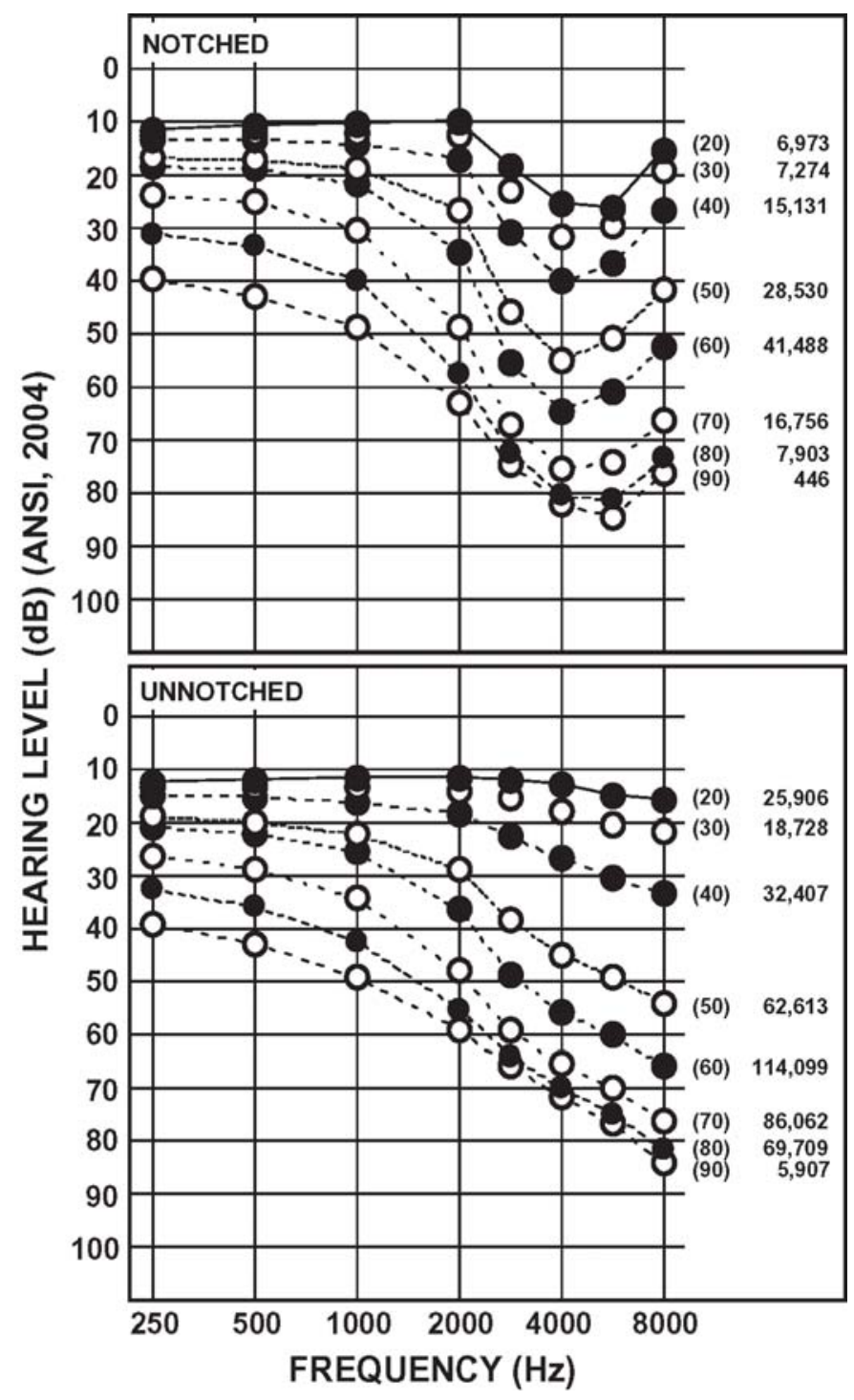

Figure 15.

Mean right ear notched and unnotched audiograms for eight age groups (indicated in parentheses). Adjacent numbers are number of participants in each group. Notched $n=124,501$; unnotched $n=445,431$. Hearing level as defined by American National Standards Institute (ANSI) [32].

for the $4,000 \mathrm{~Hz}$ data in Figure 10, except the data in Figure 16 include the 3,000 and 6,000 Hz thresholds.

\section{DISCUSSION}

As indicated in the "Introduction," this study proposed to extend the findings regarding high-frequency

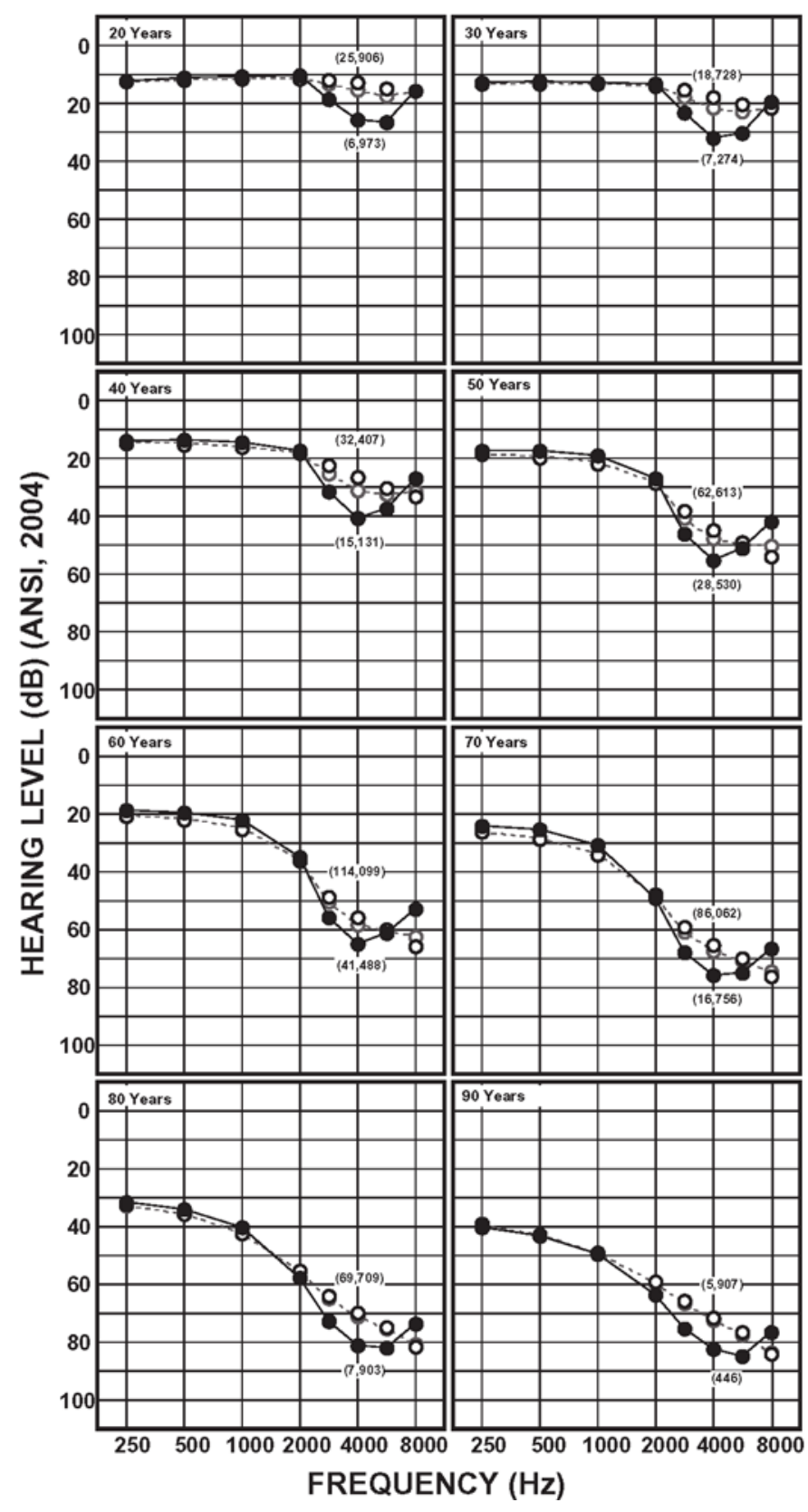

Figure 16.

Mean right ear notched (filled circles) and unnotched (black open circles) audiograms for eight age groups. Gray open circles are average audiogram for the two groups in each panel. Numbers in parentheses indicate number of participants in each group. Hearing level as defined by American National Standards Institute (ANSI) [32].

notched audiograms from a previous local group of veterans $(n=3,430)$ to a substantially larger group that represented veterans from across the country. The mean ages 
of the participants in both studies were similar, 63 yr. In the original Wilson study [28], only audiometric notch data at $4,000 \mathrm{~Hz}$ were examined because the majority of the participants did not have thresholds at 3,000 and $6,000 \mathrm{~Hz}$; the larger number of participants in the current study permitted examination of data from these two additional high frequencies. With the original report involving 3,430 veterans, 41.1 percent had a $4,000 \mathrm{~Hz}$ notch in at least one ear (15.4\% bilateral, $13.8 \%$ LE unilateral, $11.9 \%$ RE unilateral). In the current group of 744,553 veterans, only 22.9 percent had a $4,000 \mathrm{~Hz}$ notch in at least one ear (6.9\% bilateral, 8.3\% LE unilateral, 7.6\% $\mathrm{RE}$ unilateral). Although the overall prevalence of $4,000 \mathrm{~Hz}$ notches is about half in the current study with the larger number of participants, the results from both studies indicate about twice as many individuals with unilateral notches as with bilateral notches. Three other direct comparisons can be made between the two studies. Consider the distribution of notches by age. In the original study [28, p. 27: Figure 2], the percentage of participants with notches was much smaller in the two earliest decades (20s and 30s) than in the middle decades, whereas in the current data, the percentage of participants with notches is relatively equally distributed from the $20 \mathrm{~s}$ through the 60s (Figure 3). In contrast to the above two relations between the two studies, the distributions of the percentage of notched audiograms (at $4,000 \mathrm{~Hz}$ ) by the nine notch depths were very similar ([28, p. 28: Figure 3] and Figure 5 in the current report). A final similarity between the two studies can be observed with the mean audiograms plotted for the unnotched participants and the notched participants ([28, p. 29: Figure 5] and Figure 10 in the current report). Interestingly, in both studies for both the unnotched and notched audiograms the largest differences between the mean data occur between the 40 and $50 \mathrm{yr}$ decades. These cross-sectional data suggest a nonlinear change in high-frequency thresholds across the age span.

The definition of the "audiometric notch" used in this project was simple to implement and at the same time provided substantial flexibility in the analyses of the data. To be considered a notch, the threshold at the target frequency had to be bordered at 2,000 and $8,000 \mathrm{~Hz}$ by thresholds that were both minimally at HLs $10 \mathrm{~dB}$ lower (better) than the threshold at the target frequency. These minimal notch criteria were the starting point, with subsequent analyses able to parse the notch depths into 17 bins in $2.5 \mathrm{~dB}$ steps. With this technique of analyses and reporting, in many instances the reader can apply his or her own notch-depth criteria and interpret the data from that point of view. For example with the $4,000 \mathrm{~Hz}$ notch data (group 1) in Figures 5, 6, and 7, if a notch depth of 10.0 to $12.5 \mathrm{~dB}$ is considered too liberal, then the 10.0 to $12.5 \mathrm{~dB}$ data can be ignored and the minimal notch depth increased to $15.0 \mathrm{~dB}$, etc.

Finally, as commented by Jerger [51], the assumption is that most high levels of noise are experienced in a sound- or free-field environment. Exposure to excessive noise in this environment would be expected under most circumstances to have an equal effect on both ears. Why, then, are there more unilateral high-frequency notches than bilateral high-frequency notches? The presence of more unilateral notches than bilateral notches prompts at least two lines of thought. First, the high-frequency notches are caused by a multitude of factors including excessive noise exposure. Second, the ears are differentially sensitive to whatever factors are eventually found to be responsible for high-frequency audiometric notches. Both lines of reasoning deserve further investigation.

\section{CONCLUSIONS}

The 4,000 Hz notch data from 744,553 participants and the 3,000, 4,000, and $6,000 \mathrm{~Hz}$ notch data from 539,932 participants reveal several new characteristics about and several relations among high-frequency audiometric notches that can be summarized as follows:

1. The mean LE and RE pure-tone thresholds are equal at 250,500 , and $1,000 \mathrm{~Hz}$, but in the higher frequencies, the mean RE thresholds are about $2 \mathrm{~dB}$ lower (better) than the corresponding LE thresholds.

2. The majority of audiogram pairs did not exhibit a high-frequency notch. With the $4,000 \mathrm{~Hz}$ data, 77.1 percent of the participants did not have a notch in either ear, whereas with the 3,000, 4,000, and $6,000 \mathrm{~Hz}$ data, 65.3 percent did not have a notch.

3. Unilateral 3,000, 4,000, and 6,000 $\mathrm{Hz}$ notches are more prevalent than bilateral notches at those same frequencies, with unilateral LE, unilateral RE, and bilateral notches having roughly the same prevalence.

4. LE 3,000, 4,000, and $6,000 \mathrm{~Hz}$ notches are slightly more prevalent than RE notches at those same frequencies.

5. Of the 63 combinations of notch frequency and ear, the most prevalent notch configuration was $6,000 \mathrm{~Hz}$ 
in the LE, followed by $6,000 \mathrm{~Hz}$ in the RE, $4,000 \mathrm{~Hz}$ in the LE, and $4,000 \mathrm{~Hz}$ in the RE. The fifth and sixth most prevalent were the 4,000 and $6,000 \mathrm{~Hz}$ combination in the LE and the 4,000 and 6,000 Hz combination in the RE. The least prevalent was the bilateral 3,000 and $6,000 \mathrm{~Hz}$ combination.

6. The prevalence of notches maximizes in the 40 to 50 yr decades, decreasing substantially in the 70 to $90 \mathrm{yr}$ decades.

7. The prevalence of unilateral $4,000 \mathrm{~Hz}$ notches was greater than the prevalence of bilateral $4,000 \mathrm{~Hz}$ notches for the two shallow notch depths (10.0 to 12.5 and 15.0 to $17.5 \mathrm{~dB}$ ), a relation that was just reversed for the notch depths $>25.0 \mathrm{~dB}$, at which the prevalence of bilateral notches was greater.

8. Notches at 3,000, 4,000, and $6,000 \mathrm{~Hz}$ are asymmetric, with the low-frequency side typically twice as deep (or steep) as the high-frequency side.

9. With the younger participants, the low-frequency side of the notch was only slightly steeper than the highfrequency side, whereas with the older participants, the low-frequency side was substantially steeper than the high-frequency side.

10. Bilateral notches on average are several decibels deeper than unilateral notches.

11. The LE and RE notch depths are about the same, with mean depths of $\sim 23 \mathrm{~dB}$. The most prevalent notch depth for $3,000,4,000$, and $6,000 \mathrm{~Hz}$ was 15.0 to $17.5 \mathrm{~dB}$.

12. The distributions of notch depths vary as a function of age, with skewed distributions at the age extremes and more normal distributions in the 40 to $60 \mathrm{yr}$ decades.

13. Comparison of the mean notched and unnotched audiograms reveals comparable thresholds 250 to $2,000 \mathrm{~Hz}$. In the higher frequencies, however, the mean thresholds for the notched group were higher (poorer) at the notch frequency, but typically lower (better) at $8,000 \mathrm{~Hz}$ than the mean thresholds for the unnotched group.

\section{ACKNOWLEDGMENTS}

This article is dedicated to the memory of Raymond Carhart, whose passion was the analysis of audiograms and audiometric data made of his meticulous records with his mechanical sorter and calculator.

Author Contributions:

Study concept and design: R. H. Wilson, R. McArdle.
Acquisition of data: R. McArdle, R. H. Wilson.

Analysis and interpretation of data: R. H. Wilson, R. McArdle.

Drafting of manuscript: R. H. Wilson, R. McArdle.

Critical revision of manuscript for important intellectual content:

R. H. Wilson, R. McArdle.

Statistical Analysis: R. McArdle, R. H. Wilson.

Financial Disclosures: The authors have declared that no competing interests exist.

Funding/Support: This material was based on work supported by the VA Rehabilitation Research and Development Service through the Auditory and Vestibular Dysfunction Research Enhancement Award Program, a Senior Research Career Scientist award to the first author, and a Career Development Award to the second author.

Additional Contributions: Appreciation is extended to the audiologists throughout the VA facilities who share in contributing to this article and to Kevin Quitmeyer, Pam Urrutia, and Mary Ann Blumenthal from the DALC, who extracted the archived data. Portions of this article were presented at the annual convention of the American Speech-Language-Hearing Association in San Diego, California, November 2011; the annual convention of the Joint Defense/VA Audiology Conference in Dallas, Texas, March 2012; and Northwestern University as part of the visiting scholar program, May 2012.

Institutional Review: The study was approved by the joint East Tennessee State University/VA Institutional Review Board (0810.2e) and by the Bay Pines VA Research and Development Committee (2842).

Participant Follow-Up: The authors do not plan to inform participants of the publication of this study because contact information is unavailable.

\section{REFERENCES}

1. Fowler EP. Marked deafened areas in normal ears. Arch Otolaryngol. 1928;8:151-55. http://dx.doi.org/10.1001/archotol.1928.00620020167004

2. Drury DW. Deafness in syphilis: an audiometric study. Ann Otol Rhinol Laryngol. 1929;38:625-56.

3. Ciocco A. Observations on the hearing of 1,980 individuals: a biometric study. Laryngoscope. 1932;42:837-56. http://dx.doi.org/10.1288/00005537-193211000-00002

4. Wever EG. The problem of the tonal dip. Laryngoscope. 1942;52:169-87.

http://dx.doi.org/10.1288/00005537-194203000-00001

5. Loch WE. Incidence and permanency of tonal dips in children. Laryngoscope. 1943;53:347-56. http://dx.doi.org/10.1288/00005537-194305000-00006

6. Lehnhardt E. The C5-dip: Its interpretation in the light of generally known physiological concepts. Int $\mathrm{J}$ Audiol. 1967;6:86-95.

http://dx.doi.org/10.3109/05384916709074237

7. Hunter-Duvar IM, Elliott DN. Effects of intense auditory stimulation: hearing losses and inner ear changes in the squirrel monkey. II. J Acoust Soc Am. 1973;54(5):1179-83. [PMID:4203137]

http://dx.doi.org/10.1121/1.1914364 
8. Cooper JC, Owen JH. Audiologic profile of noise-induced hearing loss. Arch Otolaryngol. 1976;102(3):148-50. [PMID:1267690] http://dx.doi.org/10.1001/archotol.1976.00780080070007

9. Clark WW, Bohne BA. Animal model for the 4-kHz tonal dip. Ann Otol Rhinol Laryngol. 1978;87(4 Pt 2 Suppl 51): 1-16. [PMID:100042]

10. Sataloff RT. The 4,000-Hz. audiometric dip. Ear Nose Throat J. 1980;59(6):251-57. [PMID:7398542]

11. Humes LE. Noise-induced hearing loss as influenced by other agents and by some physical characteristics of the individual. J Acoust Soc Am. 1984;76(5):1318-29. [PMID:6512095] http://dx.doi.org/10.1121/1.391447

12. Henderson D, Subramaniam M, Boettcher FA. Individual susceptibility to noise-induced hearing loss: an old topic revisited. Ear Hear. 1993;14(3):152-68. [PMID:8344472] http://dx.doi.org/10.1097/00003446-199306000-00002

13. Murai K. Investigation of the 4,000-Hertz dip by detailed audiometry. Ann Otol Rhinol Laryngol. 1997;106(5):408-13. [PMID:9153106]

14. Luxon LM. The clinical diagnosis of noise induced hearing loss. In: Prasher DP, Luxon LM, editors. Advances in noise research. Volume 1: Biological effects of noise. London (UK): Whurr Publishers; 1998. p. 83-113.

15. Committee on Noise-Induced Hearing Loss and Tinnitus Associated with Military Service from World War II to the Present. Noise-induced hearing loss. In: Humes LE, Joellenbeck LM, Durch JE, editors. Noise and military service: Implications for hearing loss and tinnitus. Washington (DC): The National Academies Press; 2006. p. 33-71.

16. Talaska AE, Schacht J. Mechanisms of noise damage to the cochlea. Audiol Med. 2007;5:3-9. http://dx.doi.org/10.1080/16513860601158887

17. Kujawa SG, Liberman MC. Adding insult to injury: cochlear nerve degeneration after "temporary" noiseinduced hearing loss. J Neurosci. 2009;29(45):14077-85. [PMID:19906956] http://dx.doi.org/10.1523/JNEUROSCI.2845-09.2009

18. Nondahl DM, Shi X, Cruickshanks KJ, Dalton DS, Tweed TS, Wiley TL, Carmichael LL. Notched audiograms and noise exposure history in older adults. Ear Hear. 2009; 30(6):696-703. [PMID:19633561] http://dx.doi.org/10.1097/AUD.0b013e3181b1d418

19. Lin HW, Furman AC, Kujawa SG, Liberman MC. Primary neural degeneration in the Guinea pig cochlea after reversible noise-induced threshold shift. J Assoc Res Otolaryngol. 2011;12(5):605-16. [PMID:21688060] http://dx.doi.org/10.1007/s10162-011-0277-0

20. Osei-Lah V, Yeoh LH. High frequency audiometric notch: an outpatient clinic survey. Int J Audiol. 2010;49(2):95-98.

\section{[PMID:20151883]}

http://dx.doi.org/10.3109/14992020903300423

21. Gates GA, Schmid P, Blinne W, Nam B, D’Agostino R. High-frequency audiometric notches in older people. J Occup Hear Loss. 1999;2:1-10.

22. McBride DI, Williams S. Audiometric notch as a sign of noise induced hearing loss. Occup Environ Med. 2001; 58(1):46-51. [PMID:11119634] http://dx.doi.org/10.1136/oem.58.1.46

23. Phillips SL, Henrich VC, Mace ST. Prevalence of noiseinduced hearing loss in student musicians. Int $\mathrm{J}$ Audiol. 2010;49(4):309-16. [PMID:20233141] http://dx.doi.org/10.3109/14992020903470809

24. Cruickshanks KJ, Wiley TL, Tweed TS, Klein BE, Klein R, Mares-Perlman JA, Nondahl DM; The Epidemiology of Hearing Loss Study. Prevalence of hearing loss in older adults in Beaver Dam, Wisconsin. Am J Epidemiol. 1998;148(9):879-86. [PMID:9801018] http://dx.doi.org/10.1093/oxfordjournals.aje.a009713

25. Coles RR, Lutman ME, Buffin JT. Guidelines on the diagnosis of noise-induced hearing loss for medicolegal purposes. Clin Otolaryngol Allied Sci. 2000;25(4):264-73. [PMID:10971532] http://dx.doi.org/10.1046/j.1365-2273.2000.00368.x

26. Dobie RA, Rabinowitz PM. Change in audiometric configuration helps to determine whether a standard threshold shift is work-related. Spectrum. 2002;19(Suppl 1):17.

27. Hoffman HJ, Ko C-W, Themann CL, Dillon CF, Franks JR. Reducing noise-induced hearing loss (NIHL) to achieve U.S. Healthy People 2010 goals. Am J Epidemiol. 2006; 163(Suppl):487.

28. Wilson RH. Some observations on the nature of the audiometric $4000 \mathrm{~Hz}$ notch: data from 3430 veterans. J Am Acad Audiol. 2011;22(1):23-33. [PMID:21419067] http://dx.doi.org/10.3766/jaaa.22.1.4

29. Ventry IM, Weinstein BE. The Hearing Handicap Inventory for the elderly: a new tool. Ear Hear. 1982;3(3):128-34. [PMID:7095321] http://dx.doi.org/10.1097/00003446-198205000-00006

30. Carhart R, Jerger JF. Preferred method for clinical determination of pure-tone thresholds. J Speech Hear Disord. 1959; 24:330-45.

31. Wilson RH, Noe CM, Cruickshanks KJ, Wiley TL, Nondahl DM. Prevalence and degree of hearing loss among males in Beaver Dam cohort: comparison of veterans and nonveterans. J Rehabil Res Dev. 2010;47(6):505-20.

[PMID:20848364] http://dx.doi.org/10.1682/JRRD.2009.10.0169

32. Specification for audiometers. ANSI S3.6 2004. New York (NY): American National Standards Institute; 2004. 
33. Ward WD. Hearing of naval aircraft maintenance personnel. J Acoust Soc Am. 1957;29:1289-1301. http://dx.doi.org/10.1121/1.1908768

34. Corso JF. Age and sex differences in pure-tone thresholds. Survey of hearing levels from 18 to 65 years. Arch Otolaryngol. 1963;77:385-405. [PMID:14041404]

http://dx.doi.org/10.1001/archotol.1963.00750010399008

35. Kannan PM, Lipscomb DM. Letter: Bilateral hearing asymmetry in a large population. J Acoust Soc Am. 1974; 55(5):1092-94. [PMID:4833703]

http://dx.doi.org/10.1121/1.1914657

36. Sutherland HC, Gasaway DC. Current hearing threshold levels for noise-exposed U.S. Air Force personnel: one year's reportings. Report SAM-TR-78-39. Brooks Air Force Base (TX): School of Aerospace Medicine; 1978. p. 1-17.

37. Axelsson A, Jerson T, Lindberg U, Lindgren F. Early noiseinduced hearing loss in teenage boys. Scand Audiol. 1981;10(2):91-96. [PMID:7280546] http://dx.doi.org/10.3109/01050398109076167

38. Chung DY, Mason K, Gannon RP, Willson GN. The ear effect as a function of age and hearing loss. J Acoust Soc Am. 1983;73(4):1277-82. [PMID:6853839] http://dx.doi.org/10.1121/1.389276

39. Pirilä T, Sorri M, Jounio-Ervasti K, Sipilä P, Karjalainen H. Hearing asymmetry among occupationally noise-exposed men and women under 60 years of age. Scand Audiol. 1991;20(4):217-22. [PMID:1842293] http://dx.doi.org/10.3109/01050399109045966

40. Pirilä T, Jounio-Ervasti K, Sorri M. Left-right asymmetries in hearing threshold levels in three age groups of a random population. Audiology. 1992;31(3):150-61.

[PMID:1642566] http://dx.doi.org/10.3109/00206099209072910

41. Cox HJ, Ford GR. Hearing loss associated with weapons noise exposure: when to investigate an asymmetrical loss. J Laryngol Otol. 1995;109(4):291-95. [PMID:7782682] http://dx.doi.org/10.1017/S0022215100129950

42. Allen PD, Eddins DA. Presbycusis phenotypes form a heterogeneous continuum when ordered by degree and configuration of hearing loss. Hear Res. 2010;264(1-2):10-20. [PMID:20144701] http://dx.doi.org/10.1016/j.heares.2010.02.001

43. Gates GA, Schmid P, Kujawa SG, Nam B, D’Agostino R. Longitudinal threshold changes in older men with audiometric notches. Hear Res. 2000;141(1-2):220-28.

\section{[PMID:10713509]}

http://dx.doi.org/10.1016/S0378-5955(99)00223-3

44. Mills JH, Boettcher FA, Dubno JR. Interaction of noiseinduced permanent threshold shift and age-related threshold shift. J Acoust Soc Am. 1997;101(3):1681-86. [PMID:9069635] http://dx.doi.org/10.1121/1.418152

45. Albera R, Lacilla M, Piumetto E, Canale A. Noise-induced hearing loss evolution: influence of age and exposure to noise. Eur Arch Otorhinolaryngol. 2010;267(5):665-71. [PMID:19760212] http://dx.doi.org/10.1007/s00405-009-1096-3

46. Bunch CC. Age variations in auditory acuity. Arch Otolaryngol. 1929;9:625-36. http://dx.doi.org/10.1001/archotol.1929.00620030657005

47. Glorig A, Davis H. Age, noise and hearing loss. Ann Otol Rhinol Laryngol. 1961;70:556-71. [PMID:13706085]

48. Rosen S, Bergman M, Plester D, El-Mofty A, Satti MH. Presbycusis study of a relatively noise-free population in the Sudan. Ann Otol Rhinol Laryngol. 1962;71:727-43. [PMID:13974856]

49. Robinson DW, Sutton GJ. Age effect in hearings-a comparative analysis of published threshold data. Audiology. 1979;18(4):320-34. [PMID:475664]

50. Brant LJ, Fozard JL. Age changes in pure-tone hearing thresholds in a longitudinal study of normal human aging. J Acoust Soc Am. 1990;88(2):813-20. [PMID:2212307] http://dx.doi.org/10.1121/1.399731

51. Jerger J. Is nothing sacred? J Am Acad Audiol. 2011; 22(1):4. [PMID:21419064] http://dx.doi.org/10.3766/jaaa.22.1.1

Submitted for publication November 23, 2011. Accepted in revised form May 17, 2012.

This article and any supplementary material should be cited as follows:

Wilson RH, McArdle R. Characteristics of the audiometric 4,000 Hz notch (744,553 veterans) and the 3,000, 4,000, and 6,000 Hz notches (539,932 veterans). J Rehabil Res Dev. 2013;50(1):111-32. http://dx.doi.org/10.1682/JRRD.2011.11.0225

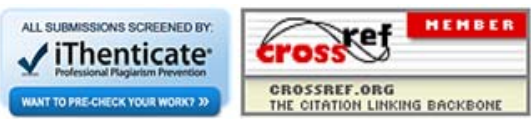

